The ten shades of silver: Segmentation of older adults in the mobile phone market

Andraž Petrovčič, Ph.D. ${ }^{* a}$, Ana Slavec, Ph.D. , Vesna Dolničar, Ph.D.*

This article was originally published in International journal of human-computer interaction 34(9): $845-860$ by Taylor \& Francis Group. The publisher's version of this article is available at: https://doi.org/10.1080/10447318.2017.1399328.

Suggested citation:

Andraž Petrovčič, Ana Slavec \& Vesna Dolničar (2018) The Ten Shades of Silver:

Segmentation of Older Adults in the Mobile Phone Market, International Journal of HumanComputer Interaction, 34:9, 845-860, DOI: 10.1080/10447318.2017.1399328.

${ }^{*}$ University of Ljubljana, Faculty of Social Sciences, Ljubljana, Slovenia

Running title: The ten shades of silver

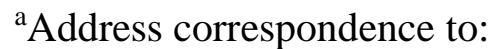

Dr. Andraž Petrovčič

University of Ljubljana

Faculty of Social Sciences

Kardeljeva ploščad 5

1000 Ljubljana

Slovenia

E-mail: andraz.petrovcic@ @dv.uni-lj.si 


\title{
The ten shades of silver: Segmentation of older adults in the mobile phone market
}

\begin{abstract}
With the closing of the age-related gap in mobile phone uptake and the aging of the population, older adults have increasingly become a desirable target group for mobile phone providers. Although abundant literature has accumulated describing the use of mobile phones amongst older adults, segmentation studies on this group of consumers remain scant and inconclusive. Drawing on the benefit and behavioral segmentation this study presents a segmentation model of older adults in the mobile phone market that incorporates a wide variety of consumer behavior, attitudinal, and acceptance variables relevant for the understanding of mobile phone (non-)usage patterns among users of feature phones and smartphones, as well as among mobile phone non-users. The model is based on a hybrid approach with a two-step cluster analysis using data collected by a telephone survey from a representative sample $(n=1,581)$ of adults aged 55 or older in Slovenia in 2015. The analysis yielded two uniquely-profiled clusters within each of the five a priori determined segments, summing to a total of 10 clusters. The results show that older adults still prefer feature phones. Nevertheless, the mobile phone market has become highly heterogeneous, with clusters of older adults having distinguishable feature phone and smartphone use patterns as well as socio-demographic and life-course profiles. Since many of these profiles undermine the notion of older adults as "basic" mobile phone users, our findings represent a solid foundation for scholars and marketers to further investigate their specific needs in relation to more advanced smartphone and mobile internet usage.
\end{abstract}

Key words: Consumer behavior; mobile phone market; older adults; segmentation; smartphone. 


\section{Introduction}

In the recent past, the number of older adults using mobile phones has rapidly increased.

Notably, the average proportion of mobile phone use among older adults aged 55 years or older has reached 83\% across EU member states in 2015 (European Commission, 2016), while only three out of $28 \mathrm{EU}$ member states had less than $80 \%$ of mobile phone users in this age group. Nevertheless, what distinguishes older adults from other population groups in terms of mobile phone use is the relatively small proportion of older adults who are smartphone users (Berenguer et al., 2017). The most recent figures from the UK show that 56\% of adults aged 55-64 years used smartphones in 2015 (Ofcom, 2016). This number was even smaller among adults aged 65-74 years (28\%) and adults older than 75 years (8\%). Likewise, in the US, the proportion of smartphone users in 2015 was 54\% and 27\% among the 50-64 and 65+ age groups, respectively (Smith, 2015). However, the pace of smartphone adoption among older adults is growing quickly (Berenguer et al., 2017). Specifically, Ofcom (2016) reports that the proportion of smartphone users increased from $9 \%$ to $56 \%$ among adults aged 55-64 years and from 3\% to $28 \%$ among adults aged 65-74 years between 2010 and 2015.

Such trends have triggered several scholarly investigations on the various adoption factors and usage patterns of different types of mobile phone devices and services among older adults. A few examples of these strands of research are Kurniawan (2008), Conci, Pianesi, and Zancanaro (2009), Kubik (2009), Chen, McGaughey, Zeltmann, Lu, and Lee (2017), Hardhill and Olphert (2012), Chen, Chan, and Tsang (2013), Petrovčič, Vehovar, and Dolničar (2016), and Seifert and Schelling (2015). Overall, these studies indicate that older adults' intention to adopt mobile phones and the intensity of their use have been shaped by a complex set of intertwined socio-technical factors which have resulted in fairly heterogeneous usage patterns and consumption styles. For instance, Hardill and Olphert (2012) found that 
older adults predominantly rely on mobile phones for keeping in touch with their closest social circles and for communicating in cases of emergency, whereas Petrovčič et al. (2016) demonstrated the focal role of mobile communication in older adults' social companionship networks. Kubik (2009) concluded that such motives were even more prominent among young older adults (defined as those under 75 years old). Likewise, Kurniawan (2008) and Chen et al. (2017) revealed that older adults show the most interest in voice calls and texting, while paying only moderate attention to mobile internet and other advanced features. Conversely, other researchers have recently shown that, for a considerable number of older adults - albeit they are still underrepresented when compared to the general population -, access to mobile internet (Gerpott, Thomas, \& Weichert, 2013; Seifert \& Schelling, 2015) and applications (Plaza, Martín, Martin, \& Medrano, 2011) are becoming a resource for coping with daily living and active aging. In particular, Doughty and Williams (2016) and Plaza et al. (2011) advanced that older adults are a potentially very appealing target group for advanced smartphone services within different models of telecare and telehealth support. Moreover, Smith (2015) showed that services such as sharing information about local events, following breaking news, and learning about community events are already popular among older adults aged 50 years and above, suggesting that they cannot be considered as only light users of mobile phone services and thus neglected as a marketing target. In fact, Sell et al. (2010b, 122) noted: "The increase in expected length of life, increased spending power and advances in health care mean the elderly now constitute a sizeable market segment which is to be taken seriously when planning future mobile services."

However, the heterogeneity of mobile phone usage patterns among older adults has been only scarcely discussed in literature dealing with the segmentation of older adults in the mobile phone market. In fact, in marketing literature, older adults are often depicted as technologically anxious and reluctant to adopt new technologies (Deng, Mo, \& Liu, 2014; 
Hur, Lee, \& Choo, 2017; Niemelä-Nyrhinen, 2007). Even when older adults are included in the sample design, they are often treated as one homogenous segment, whose needs, behaviors, and attitudes towards new technologies are evaluated on the general population dimensions. According to Sell, Walden, and Carlsson (2010b), overgeneralization might be an important analytic constraint when investigating consumer segments in a mobile market, as overgeneralization can make it more difficult to explore the benefits and barriers for the different segments, particularly when dealing with the specifics of mature market segmentation (e.g., Moschis, 2003; Sudbury \& Simcock, 2009).

Furthermore, even the few studies that specifically focus on the segmentation of older adults in the mobile phone market employ a very limited basis for breaking down this consumer segment into sub-segments. For instance, Vicente and Lopes (2016) use only attitudes toward mobile phones as clustering variables in their segmentation model, whereas other consumer and user characteristics such as intensity of use, monthly mobile phone expenses, and type of service plan are entered into the model as independent variables. In addition, existing segmentation studies neither compare the potential differences between segments of mobile phone non-users, feature phone users, and/or smartphone users, nor are they particularly helpful in assessing how the benefits sought by older adults are in turn related to facilitating factors of and/or barriers to the adoption of different types of mobile devices and services.

The above research gaps pose challenges to a more comprehensive understanding of the roles and needs of older adults in the mobile phone market. One way to investigate the development and marketing of smartphone services that would be more effectively geared toward the needs and characteristics of older adults is through user profiling and segmentation based on their perceived benefits and behavioral patterns related to mobile phone (non-)use. As part of addressing this issue, the aim of this study is to propose a conceptual integration of 
the behavioral and benefits segmentation technique, supported by an empirically-based segmentation model of older adults in the mobile phone market in Slovenia that incorporates a wide variety of consumer behavior and attitudinal variables relevant for the understanding of mobile phone (non-)usage patterns. We will subsequently associate the identified clusters in the segmentation model to socio-demographic and life-course characteristics to gain a better insight into how one or more of the clusters derived from the model may be (more) effectively targeted by marketers.

In what follows, we will first briefly discuss the segmentation literature and prior research in the mobile phone domain in order to explore the segmentation models of older adults and their characteristics in terms of behavioral patterns and benefits associated with the (non-)use of the mobile phone. Next, we will introduce the derived research questions addressed in this study. Afterwards, we will present our research design and the results of the segmentation model. The paper will conclude with a discussion of the findings, presentation of limitations, implications, and future research.

\section{Literature review}

\section{Older adults as consumers of mobile phone services}

Early segmentation studies of the mobile market did not focus on older adults specifically but rather described them as portions of consumer segments in the general population. For instance, Anckar and D'Incau (2002) conducted a segmentation study in Finland on a sample aged 16-74 years to identify the primary target groups in the general population for various mobile services and to explore the consumers' willingness to use a number of mobile services (i.e., m-willingness). In general, older adults reported a much lower m-willingness than the other age groups, particularly the youngest respondents, albeit their m-willingness for entertainment-related mobile services was surprisingly high (Anckar \& D'Incau, 2002). Further, Okazaki (2006) focused on the segmentation of mobile internet adopters with a two- 
step cluster analysis of a sample of individuals who regularly used email via mobile phones. The authors identified four clusters of mobile internet adopters, two of which were associated with older adults who reported relatively positively-valued mobile internet services.

Moreover, Mazzoni, Castaldi, and Addeo (2007) applied a multidimensional segmentation design based on consumer/user lifestyles, user motivations, and product/service attributes using a representative sample of Italian mobile phone users aged 14-65 years. They identified three groups of mobile phone users; the highest proportion of older adults was in the basic users cluster, consisting of $37.4 \%$ of the sample. Mazzoni et al. (2007) suggested that, for basic users, the mobile phone is a convenient tool for communication and management of social ties. In fact, basic users utilized mobile phones mostly for socializing gratifications (e.g., to call and text their friends and relatives) and assigned strong value to their practical attributes, such as ease of use, battery life, screen visibility, and durability. Consequently, they reported scarce interest in the aesthetics functions of mobile devices, such as personalization options.

Low interest among older adults for customizing mobile phones was also found by Sell, Walden, and Carlsson (2010a; 2010b), who carried out segmentation studies with users of mobile phones and services on random samples of the general population (16-64 years old) in Finland. Sell et al. (2010a, 2010b) showed that older adults and retired people, were primarily associated with a high score on the basic factor, which indicated a low interest in new technologies and a consumption style characterized by the use of only the most basic functions of the phone, such as voice calls and texting. Respondents in this group used a mobile phone significantly less frequently than the other four groups. They felt it took too much time and effort to learn how to use mobile services, and they had a higher sense than other groups that they did not need mobile services. Thus, they also expressed very low intention to start using internet-based mobile services, such as email and web browsing, in the 
future. Accordingly, respondents in the basic segment were using basic feature phones without internet access.

In a subsequent segmentation study that also included also smartphone users, Sell, Mezei, and Walden (2014) confirmed most of their earlier findings. Again, they clustered respondents from a random sample, aged 16-64 years, of the Finnish general population, but this study implemented a latent class analysis which measured consumers' perceptions of the benefits to be gained from using mobile technology and their personal innovativeness and self-efficacy, as well as social aspects of using mobile technology. The results indicated three clearly distinguishable segments with the conservative segment having the highest average age (51 years) and the smallest percentage of smartphone users (15\%). Conservative consumers used the mobile phone predominately for calling and texting, while they had never tried the mobile email, calendar/agenda, and navigation services. Moreover, they also felt that mobile services in general were difficult and cumbersome to use, showing very low interest for new mobile services and reporting experimentation with innovations on the market only when absolutely necessary.

In contrast with prior research, Hamka et al. (2014) focused exclusively on the segmentation of smartphone users. They identified three clusters of smartphone users with a considerable proportion of older adults (Hamka et al., 2014). On one hand, when they clustered the sample based on the average number of calls per day, average SMS messages per day, average WLAN data per day, and average data on cellular connection per day, the highest percentage of smartphone users aged 55-64 years was among WLAN-only users. They were characterized by low usage on voice, SMS, and data through their cellular connection but medium usage for WLAN connection. On the other hand, clustering based on the average number of URLs visited per day, average number of applications run per day, and average number of applications installed per day, resulted in two clusters with a significant proportion 
of older adults. Application ignorants requested a low number of URLs and made limited use of built-in and installed applications, whereas information seekers requested a high number of URLs but also showed low usage of applications. While both clusters were characterized by highly-educated individuals with full-time jobs and above-average income levels, application ignorants were more likely to be above-average aged females, while information seekers were predominately males.

However, lower intensity of smartphone service use does not necessarily imply that older adults are not seeking for and expecting a high-quality service. When Chung, Park, Koh, and Lee (2016) studied the relationships between user satisfaction and user values from the perspective of the user retention of a smartphone service provider on a general representative sample, aged 13-69 years, in Korea, they found that in the segment with the highest proportion of users aged 50 and above the importance of "Fundamental services/functions" and "Cost/monetary benefits" offered by the provider strongly predicted users" overall satisfaction with the provider. Their results also showed that contrary to the general perception older adults are not characterized by the longest subscription duration, but are rather distinguished by shorter retention periods than segments with predominantly middleaged and younger users.

In response to the realization that older adults on their own represent a considerable segment of the mobile phone market and that this group of consumers has been almost completely overlooked by practitioners and scholars, more specific mature market segmentation models were solicited (e.g., Berenguer et al., 2017; Sell et al., 2010b). However, very little segmentation research has focused exclusively on older adults with exception of Lee (2007) and Vicente and Lopes (2016). Lee (2007) explored a sample of 154 older adult mobile phone users aged from 56 to 90 years, finding three segments, partitioned by their mobile phone usage behavior. Namely, explorers (30\% of the sample) were composed of 
relatively young old people (with an average age of 68 years) who were more likely to be early adopters with high-end handsets. They combined various communication features with additional functional ones like camera, ringer change, and calculator. They felt as though they had a good knowledge of their current mobile phone and perceived it as easy to use. This group desired more features in their mobile phone, such as a camera and a calendar. Conversely, basicians (41\%) expressed interest in only the most essential features. In fact, they appeared to have limited knowledge of their phone and perceived it to be difficult to use. Moreover, most of the time, this group used the mobile phone only for communication purposes. In this sense, basicians were very similar to the third group, named minimalists (29\%). Among the three segments, this group was the oldest and was composed of very late adopters with very limited knowledge of their phone and with low-end handsets that were used in case of emergencies only. Features desired by this group included call, receive, emergency call, phone book, speed dial, and voice message.

Three distinct clusters were also described by Vicente and Lopes (2016). They clustered older adults according to their attitudes toward mobile phones, describing the underlying differences between them in terms of usage, key values toward mobile phone communications, and socio-demographic profiles. The apathetics represented almost one third of the sample; they only valued the mobile phones as a communication device and were indifferent to other aspects of the mobile phone experience (i.e., working tool, social status device). This segment contained the highest percentage of people aged 75 years or older and many females (who were very likely widowed and living alone). In general, for apathetics, a mobile phone provided a sense of security or safety, because it allowed them to contact family members in case of emergency.

Next, the social and hedonic cluster was composed of respondents who most valued a mobile phone as a social status object and expressed highly negative feelings related to the 
disturbance of privacy and tranquility and the risk of addiction. As with apathetics, their use of mobile phones was generally limited to voice communication. However, they also reported taking pictures with the phone camera. They represented the smallest cluster, which was characterized by low educational attainment.

The busy and active cluster was still professionally active. The mobile phone was mostly perceived as a useful working tool in their professional lives. This was reflected in their more intensive and frequent use of advanced features, such as mobile internet, agenda, phone camera, and email exchange, than in the other two groups. Moreover, in contrast to the social and hedonic cluster, they did not associate mobile phones with addictive behaviors or privacy constraints. They were the youngest of the three clusters and were more likely to be employed, have a higher educational level, belong to upper social classes, and live in urban areas.

\section{Behavioral and benefit segmentation criteria}

As indicated in the previous section, older adults have been shown to differ across a number of segmentation criteria in the mobile phone market. Existing segmentation models and user profiles have emphasized the importance of older adults' attitudes, motivation, and/or abilities to use or acquire mobile phone devices and services which can be associated with the behavioral (Hamka et al., 2014) and benefit segmentation models (Chung et al., 2016, Lee et al. 2015) of consumers in the mobile phone market.

Behavioral criteria include frequency of mobile phone use (Hamka et al. 2014), use of mobile phone functions (Hamka et al. 2014; Sell et al. 2010a; 2010b; 2014), type of handheld device used, duration of mobile phone use, expenditure for mobile phone services, types of service-plan (Lee 2007), and user retention (Chung el al. 2016). Behavioral patterns are also an outcome of the actual and perceived benefits older adults' desire from the mobile phone service (Chung el al. 2016). According to Haley (1968) the benefits that are pursued by 
consumers shape their behavior and, in turn, work as attitudinal antecedents of consumption. In contrast with the behavioral patterns of products consumption and usage, benefits can also reveal the motivational schemes that can explain consumer preferences for product features and attributes (Huffman, Ratneshwar, \& Mick, 2005). While Greenberg and Schwartz McDonald (1989) proposed benefit segmentation as a better technique to understand how consumers' value systems and attitudes influence their actions in the market, Ahmad (2003) underscored its utility and appeal for identifying and targeting older consumers.

Prior segmentation literature indicates that benefits were addressed in terms of gratifications sought by older adults in using mobile phones (Mazzoni et al. 2007), importance of usability aspects and features availability (e.g., ease of use, battery life, screen visibility, and durability) (Lee 2007), user satisfaction (Chung et al. 2016), preference for specific type of handsets (Lee 2007), key values and attitudes towards mobile communications (Vincente \& Lopes 2016), as well as openness for new services and technological innovation (Anckar \& D’Incau 2002; Sell et al. 2010a; 2010b; 2014).

Interestingly, however, in a viewpoint of the benefit segmentation existing profiling of older adults has been rarely based on the importance of acceptance factors derived from the Senior Technology Acceptance Model (STAM) (Renaud \& van Biljon, 2008) and Unified Theory of Acceptance and Use of Technology (UTAUT) (Venkatesh, Morris, Davis, \& Davis, 2003). Both theories have been used in past studies to investigate the mobile and smartphone adoption amongst older adults. Factors such as perceived ease of use (e.g., Conci et al., 2009), perceived usefulness (e.g., Guo, Sun, Wang, Peng, \& Yan, 2012), enjoyment (e.g., Choudrie, Pheeraphuttharangkoon, Zamani, \& Giaglis, 2014), resistance to change (e.g., Deng et al., 2014), social influence (e.g., Conci et al., 2009), compatibility (Xue et al., 2012), anxiety related to mobile phone use (e.g., Deng et al., 2014), and facilitating conditions (Choudrie et 
al., 2014), have been revealed to be associated with the intention and/or actual use of mobile phone devices and services among older adults.

Likewise, segmentation models explaining older adults' use of mobile phones have also selectively focused on factors related to older adults' self-assessment of how their material conditions, motives, usage patterns and skills shape and interact with their recognition and acceptance of the potential benefits offered by using mobile phones. In Van Dijk’s (2006) multiple access model as well as Lee and Kim's (2014) mobile divide model such factors have been conceived as important mediators of age-related digital inclusion. In fact, predictors such as price sensitivity, technology-related knowledge, self-efficacy and skills, mobile phone anxiety and privacy concerns, as well as health and age-related impairments have been also indicated as important determinants of how older adults experience the benefits of new mobile services and functions across various domains of their everyday life (Chen et al., 2017; Lee \& Kim, 2014; Roque \& Boot, 2016; Zhou, Rau, \& Salvendy, 2013).

Since Greenberg and Schwartz McDonald (1989) suggested that product and service specific motivations, perceptions, requirements and barriers are needed to obtain a viable person-based benefit segmentation, taking into account also these two groups of acceptance factors of perceived and experienced benefits can provide an opportunity to gain a more nuanced insight into the heterogeneity of older adults in the mobile phone market and can represent a foothold for the development of new services better tailored to older adults' requirements.

\section{Research questions}

To examine the characteristics of segments of older adults in the mobile phone market according to their behavioral patterns of and benefits for (non-)using mobile phones, we 
combined the behavioral and benefit segmentation approach. Our research questions for this study were:

RQ1: What distinguishable clusters exist among older adults in terms of their (non-) use of mobile phones?

RQ2: How are the identified clusters of older adults in the mobile phone market associated with their socio-demographic and life-course characteristics?

\section{Method}

\section{Data collection}

The data used in this study were collected with a telephone survey in autumn 2015 by university research team as part of an applied research project on the adoption of smartphones amongst older adults that was partly co-founded by the second largest mobile operator in Slovenia. Following Bone Fitzgerald's (1991) meta-analysis of mature segmentation studies which indicated 55 years as a common chronological age as beginning of maturity in marketing research, the target population in this study were residents of Slovenia aged 55 and older.

The initial sample of 6,675 individuals with a landline or mobile phone number was obtained from the Central Population Register administrated by the Statistical Office of the Republic of Slovenia (SORS) using random sampling with stratification by age, sex, type of settlement (i.e., urban, rural), and the region of residence. The number of individuals sampled within each stratum was proportional to the population size. The data collection resulted in 1,581 completed survey interviews which represent the total number of respondents (i.e., the realized sample). The response rate was 23.9\% (using RR2 formula in AAPOR (2016) standard definitions). To correct for over- and under-representation, data was weighted by age, gender, region, and type of settlement (i.e., control variables) using the raking method 
(Kalton, 1983) so that the marginal totals for control variables correspond to population estimates provided by the SORS.

\section{Sample}

As shown in Table 1, the realized sample of 1,581 respondents was $45 \%$ male, $44 \%$ of respondents were aged 55-64 years, and 7\% of the respondents were aged 85 years or more. Fifteen percent of respondents in the sample had some college or university education; $85 \%$ were retired, while $15 \%$ of respondents were still working. Around $45 \%$ had worked in highskill occupations. In the sample, there were $72 \%$ married respondents, while $20 \%$ were widowed; 92\% reported having children. Twenty percent said they were living in one-person households, although two-person households were the most frequent (46\%) household size. Sixty-three percent of the sample lived in one-generation households, and half (51\%) of the sample reported a household income below 1,300 euro per month. In addition, $51 \%$ of the sample lived in rural settlements with less than 2000 inhabitants, while one out of four $(25 \%)$ respondents was living in Central Slovenia.

Almost all (97\%) respondents in the sample had access to a landline phone in the household, and $98 \%$ of those respondents also used it (Table 2). Eighty-two percent of the sample had heard about smartphones, and almost $40 \%$ of those who had heard about smartphones said their familiarity with smartphones was very low. Nine out of ten $(90 \%)$ respondents were mobile phone users. Among them, $27 \%$ used a feature phone, whereas $73 \%$ were smartphone users. Further, $93 \%$ of mobile phone users had their own device, $92 \%$ have bought a new device, $22 \%$ had a prepaid plan, $28 \%$ used a mobile phone that was more than four years old, and $84 \%$ used their phone every day or almost every day. Interestingly, $53 \%$ of respondents in the sample had used a computer in the last three months, and, among them, $75 \%$ used it every day or almost every day; meanwhile, $51 \%$ had used the internet in the last three months, and, among them, $75 \%$ used it every day or almost every day. 


\section{Segmentation model}

The segmentation was based on the hybrid approach (Wind, 1978), which combines an $a$ priori segmentation design, wherein the researcher decides beforehand on a basis for segmentation, with a clustering-based segmentation design, in which segments are determined on the basis of a cluster analysis of respondents on a set of relevant variables. According to Wind (1978), a hybrid approach is particularly useful when the first level of segmentation is based on characteristics of the target population that a priori determine the product usage or product-related behavior. For example, in order to assess how often a person uses a mobile phone, the researcher must first assess whether that person is a mobile phone user or a non-user. Thus, in this study, the realized sample was first divided into five a priori segments that were derived from four variables: use of a mobile phone (non-users vs. users), type of a mobile phone device (feature vs. smartphone), acquaintance (i.e., has a respondent ever heard about a smartphone) and familiarity (i.e., how well does a respondent know what is a smartphone) with smartphones. Afterwards, the respondents in each a priori segment were clustered according to the variables that were defined as the basis for the segmentation in the selected a priori segment.

\section{Measures}

The variables used as bases for clustering (i.e., dependent variables) included two groups of measures. The first group was related to behavioral measures, including landline access and use in the household, mobile phone ownership, type of device (new vs. secondhand), age of device, use frequency, service plan, mobile phone service provider, and use of mobile phone features. These measures were derived and adapted from measures suggested in the literature dealing with mobile phone use among older adults (see Table 3 for a complete list of measures used in the analysis). The second group enclosed measures of factors associated with benefits, including a block of items rating respondents' (dis)agreement with barriers for 
non-use of mobile phones as well as nine multi-item scales of adoption factors adapted from the STAM (Renaud \& van Biljon, 2008) and UTAUT (Venkatesh et al., 2003) constructs (Table 3). ${ }^{1}$ All items were scored on 5-point Likert-type (dis)agreement scales ranging. All of the multi-item scales showed to be in the acceptable reliability range. ${ }^{2}$

Due to the hybrid approach, the variables used as bases for clusters differ across diverse segments (see Table 3). For example, the basis for segmentation of non-users of mobile phones were variables that assessed landline use at home and measured the (dis)agreement of respondents with barriers for non-use of mobile phones, whereas smartphone users were clustered according to all behavioral measures as well as acceptance factors.

The cluster descriptors (i.e., independent variables) included socio-demographic and life-course characteristics of older adults shown in Table 4. These measures were also adapted from prior research on segmentation of older adults in the mobile phone market (e.g., Sell et al., 2014; Vicente \& Lopes, 2016). Before the fielding phase, the questionnaire was pre-tested with predominantly academic experts, as well as with cognitive interviews and a small-scale pilot survey on a sample of the target population, in order to improve its validity. ${ }^{3}$

\section{Analysis}

The statistical analysis was carried out in two stages. In the first stage, the two-step cluster analysis in SPSS was run to determine the clusters within each of the five a priori defined segments. This method had been used by several researchers for clustering large data sets with mixed attributes of mobile phone users (e.g., Haverila, 2013; Lee, 2007; Okazaki, 2006; Sell et al., 2014). It is based on a probabilistic model in which the distance between two clusters is equivalent to the decrease in log-likelihood function as a result of merging (Chiu,

\footnotetext{
${ }^{1}$ See Table A1 in the Appendix for a complete list of items.

2 The results are available from the corresponding author on reasonable request.

${ }^{3}$ The results of the pre-fielding studies are available from the corresponding author on reasonable request.
} 
Fang, Chen, Wang, \& Jeris, 2001). First, original cases are grouped into preclusters using a likelihood distance measure as the similarity criterion. Cases are assigned to the precluster that maximizes a log-likelihood function. Afterwards, the standard agglomerative clustering algorithm is used to group preclusters into a range of solutions, which is then reduced to the best number of clusters on the basis of Akaike's information criterion (AIC). In contrast with other similar methods, the two-step cluster analysis can deal with both continuous and categorical variables. In the second stage, for each descriptor the chi-squared test (for categorical variables) or t-test (for continuous variables) was used to determine whether there was a significant difference between clusters within each of the five a priori determined segments.

Due to respondents giving invalid answers (i.e., item nonresponse) on selected variables used as a basis for segments (e.g., mobile phone age, type of service plan) and/or descriptors (e.g., household income, occupation status), which were most often caused by explicit refusal or "don't know" answers, the cluster analysis was run on 1,132 eligible respondents who provided valid answers on analyzed variables. ${ }^{4}$

\section{Results}

According to the values of AIC (see Table A2), the optimal number of clusters within each of the five segments was two, because the largest ratio of distances was calculated for two clusters. Thus, the two-step cluster analysis yielded 10 clusters in total (Figure 1). Based on the profiles to be discussed, the clusters were given names. In the following section, the most important variables and their corresponding categories contributing to cluster membership will be discussed. While other variables also contribute significantly, we decided to focus only on a smaller number of them in order to make the recall for reference and discussion

\footnotetext{
${ }^{4}$ The comparison between the groups showed that there were no significant differences between them on any of the socio-demographic variables, which were used as controls in the weighting procedure.
} 
more manageable. The values of variables used as a basis for segmentation are reported for each cluster in Table 3, while the values of descriptors are reported by cluster in Table 4 . Resigned stragglers $(\mathrm{n}=78)$ do not use a mobile phone and represent $7 \%$ of respondents in the sample. Only a few (6\%) of resigned stragglers had used a mobile phone in the past, while $7 \%$ of them had heard about smartphones. Almost all (99\%) resigned stragglers do not use the internet or computers. They hardly associate mobile phone with any kind of personal or general benefit. Their agreement with all reasons for not using mobile phones is stronger in comparison with uninterested opt-outers - with exception of the statement "I don't have a real need," to which, however, both groups report the strongest agreement. Resigned stragglers are significantly less likely to be young older adults (only $18 \%$ are aged 55-64 years). They are more likely to be from rural areas; around 48\% live in villages of up to 500 inhabitants. They live in small-size households, with $33 \%$ in one-person households; half $(50 \%)$ have an income of less than $700 €$ per month. Compared to uninterested opt-outers, there is a significantly higher percentage of widows (42\%) and respondents with one or more health impairments (52\%) among resigned stragglers. Uninterested opt-outers $(\mathrm{n}=57)$ represent $5 \%$ of older adults in the sample. Thirtyseven percent of this group had used a mobile phone in the past, while $80 \%$ had heard about smartphones; both shares are significantly higher in comparison to resigned stragglers. Uninterested opt-outers are significantly more likely to be younger than uninvolved stragglers; about $28 \%$ are 55-64 years old. They are significantly more likely than resigned stragglers to live in a mid-size settlement, as only $28 \%$ of them live in villages of up to 500 inhabitants. Only $11 \%$ of uninterested opt-outers live in one-person households and, in contrast to resigned stragglers, $74 \%$ of them are married or cohabiting with a partner. The largest percentage (43\%) of uninterested opt-outers has a monthly household income between 
701 and $1,000 €$. Moreover, they are significantly more likely to be regular users of computers $(14 \%)$ and the internet $(13 \%)$ than resigned stragglers.

Better-off phone offliners $(\mathrm{n}=75)$ represent $7 \%$ of older adults in the sample and are a smaller group than frugal callers. Both have never heard about smartphones despite all being feature phone users. Albeit better-off phone offliners are significantly less likely to own very new mobile phones, they use them significantly more frequently when compared to frugal callers. In fact, $7 \%$ of better-off phone offliners have a feature phone that is up to one year old, and $90 \%$ of them say they use it daily or almost daily. In addition, they are also significantly more likely than frugal callers to use the on-screen clock (86\%), texting (92\%), photo camera (50\%), calendar (27\%), and alarm clock (30\%). In contrast with frugal callers, they report using a mobile phone for listening to the music and radio $(5 \%)$ and playing games (4\%). Seventy-nine percent of better-off phone offliners have a subscription plan, which is significantly higher than among frugal callers. Moreover, they report also significantly higher educational attainment than frugal callers; attainment of some higher education is measured at $14 \%$ vs. $2 \%$. One out of ten (12\%) has been working, which is significantly more than among frugal callers, and $43 \%$ of them have had a high-skilled occupation, which is also significantly more than the total share in this segment. They have significantly higher income than frugal callers, with $77 \%$ having a household income of up to $1,500 €$ per month.

Frugal callers $(\mathrm{n}=101,9 \%)$ have quite outdate devices as $54 \%$ have a feature phone more than four years old. About two thirds (67\%) of them use the feature phone almost daily, which is significantly less when compared with better-off phone offliners. In general, they use a mobile phone for calling, while their use of other features, with the exception of mobile internet services, is less likely in comparison with better-off phone offliners. For example, only $55 \%$ use the on-screen clock, and $9 \%$ use the flashlight, whereas all other features are used by less than $7 \%$. Frugal callers are significantly more likely to be using a prepaid card 
than better-off phone offliners. Only a handful of frugal callers (2\%) have high educational attainment, have worked in a high-skill occupation (17\%), and are still working (4\%). They are significantly more likely to be internet $(90 \%)$ or computer $(89 \%)$ non-users compared to better-off phone offliners ( $46 \%$ and $51 \%$, respectively).

Old-fashioned quitters $(\mathrm{n}=168)$ represent $14 \%$ of respondents in the sample and are therefore more numerous than active socializing onliners in the third segment of feature phone users who have heard about smartphones but have little knowledge about them. The percentage of mobile phone owners $(93 \%)$ among the old-fashioned quitters is significantly smaller when compared to active feature phone onliners. A scarce half (49\%) of Oldfashioned quitters have a feature phone more than four years old. Around $62 \%$ use it daily, and they report using fewer functions than their segment total. Approximately 55\% of respondents in this cluster have a subscription, which is significantly less compared with the other clusters in this segment. Among the reasons for not using smartphones, old-fashioned quitters, in comparison with active socializing onliners, report, on average, significantly stronger agreement with statements related to privacy concerns, feeling too old, excessive service costs, the fear that a smartphone would limit their freedom, not having a real need, and phone radiation concerns. In comparison with active socializing onliners, they are also significantly more likely to be older, to have a lower educational level, to have worked in low-skill jobs, to live in East Slovenia, to have a smaller household income, and to be married or living with a partner, while the percentage of widows among them is above the segment total percentage. In addition, less than half (48\%) of old-fashioned quitters consider their health status to be good or very good; this is a significant difference of 12 percentage points less in comparison with active socializing onliners.

Active socializing onliners $(\mathrm{n}=146,13 \%)$ are significantly more likely than oldfashioned quitters to use the handsets on a daily basis and have their own feature phone 
(98\%). Moreover, they are also more likely to have a newer device; around $18 \%$ have one that is up to one year old. They are more likely to use more features than old-fashioned quitters, not limited to the on-screen clock (94\%), texting (90\%), camera (74\%), calendar (47\%), alarm clock (42\%), and flashlight (24\%), but including also email (5\%), web browsing (4\%) and listening to music or the radio (6\%). Nine out of ten (90\%) have a subscription plan, which is significantly more compared to the other group in this segment. Active socializing onliners do not use smartphones mostly because of privacy concerns, followed by excessive service costs and negative feelings regarding an expectation that a smartphone would limit their freedom. Moreover, they are also significantly more likely to be computer (57\%) and internet users (56\%) when compared with old-fashioned quitters (25\% computer and $23 \%$ internet).

Privacy-struck savvy eagers $(\mathrm{n}=106)$ represent $9 \%$ of respondents in the sample. Even though they have heard about smartphones and have at least some knowledge about them, they continue using a feature phone. In comparison with informed safeplayers, the other group in this segment, they are significantly more likely to use newer feature phones. Moreover, there is a significantly larger proportion of privacy-struck savvy eagers to report using features such as the on-screen clock (97\%), text messaging (98\%), camera (85\%), calendar (65\%), alarm clock (66\%), flashlight (41\%), web browsing (9\%), maps and navigation (8\%), listening to music or the radio (11\%) and internet television (4\%). Their decision not to use a smartphone is most likely related to privacy concerns, while not having a real need and health impairments are the least concerns. Nevertheless, they express significantly less strong agreement with all barriers than informed safeplayers. Moreover, although privacy-struck savvy eagers report having adequate knowledge, money, and support to start using a smartphone, and they feel that smartphones are compatible with their lives and are easy to use, they consider a smartphone to be only somewhat useful and therefore show somewhat modest interest for starting to use one in the future. They are significantly more 
likely than informed safeplayers to have finished at least high school, to work in high-skill occupations, and to be active in the labor market. Consequently, they also report a significantly higher household income. Almost three out of four (73\%) privacy-struck savvy eagers claim to be healthy or very healthy, and only $3 \%$ say they receive domestic help. Among privacy-struck savvy eagers, $81 \%$ use the internet, and $84 \%$ use a computer regularly; more than half (56\%) say they have good or very good internet skills. In this sense, they are performing significantly better than informed safeplayers.

Informed safeplayers $(\mathrm{n}=117,10 \%)$ use feature phones that are significantly older than the ones used by privacy-struck savvy eagers. They are significantly less likely to use internet-based features such as web browsing and email on a feature phone. They do not adopt smartphones because of privacy concerns, because they feel too old, and because of excessive service costs, while health impairments are the least important factor for them. Informed safeplayers will be significantly less likely to start using a smartphone in the future than privacy-struck savvy eagers. Accordingly, they also agree significantly less strongly, on average, with all STAM and UTAUT factors. Besides being more likely to have low educational attainment and a low-skill occupation, informed safeplayers are also more likely to be retired and have a lower household income than privacy-struck savvy eagers. In fact, the largest percentage (29\%) of informed safeplayers live in households with a monthly income between 701 and 1,100€, while $8 \%$ live in households with an income above 2,100€. Only about half $(52 \%)$ of informed safeplayers are in good or very good health, which is below the segment total percentage. They are significantly less likely to be internet and computer users when compared to privacy-struck savvy eagers.

Smartphone well-off netizens ( $\mathrm{n}=168)$ account for $15 \%$ of the sample and, together with reluctant smartphone essentialists, represent the segment of smartphone users. Smartphone well-off netizens use several smartphone features. In particular, they are more 
likely than the other group to be users of features such as calendar (83\%), email (83\%), web browsing (90\%), maps and navigation (62\%), internet television (45\%), online social networks (40\%), and games (11\%). They are also more likely to be on a subscription plan (97\%) and report a higher monthly expenditure for their mobile phone plan. When compared with reluctant smartphone essentialists, they report, on average, being more compatible with their smartphone and enjoying better facilitating conditions and a stronger intention to continue with its use in the future. They also express a significantly stronger agreement about smartphones being useful, enjoyable, and easy to use. Smartphone well-off netizens are significantly more likely to be males with a high educational attainment level than reluctant smartphone essentialists. They also significantly differ from the latter in terms of the percentage of labor-active individuals (41\%), the share of those who have worked in highskill occupations (67\%), and the percentage of older adults reporting good or very good health status (78\%). Moreover, in this group there is also a significantly higher percentage of internet (98\%) and computer (96\%) users, as well as respondents who use the internet (91\%) or computers $(96 \%)$ on a daily basis. Accordingly, $78 \%$ of smartphone well-off netizens say their internet skills are good or very good; that is significantly more than within the other group in this segment.

Reluctant smartphone essentialists $(\mathrm{n}=121,11 \%)$ use several smartphone features, although significantly fewer than the other group in this segment. In particular, this group has a significantly smaller proportion of email users (12\%), web users (11\%), and users of maps and navigation (10\%), as well as respondents who use their smartphones for listening to music $(9 \%)$. The percentage of reluctant smartphone essentialists who watch internet television, interact on online social networks, or play games on their smartphones is below $3 \%$. These findings are in line with the results showing that among reluctant smartphone essentialists, $81 \%$ use the internet almost daily, and $82 \%$ use a computer (almost) daily. 
Moreover, $53 \%$ of essentialists report having good or very good internet skills - all percentages significantly lower when compared to smartphone well-off netizens. Further, reluctant smartphone essentialists express significantly lower agreement with all technology acceptance factors than smartphone well-off netizens, with the only exception being mobile anxiety, which is significantly higher among the former. The biggest absolute differences in average agreement are related to intention for future use and factors of enjoyment, social influence, compatibility, perceived ease of use, and perceived usefulness. In contrast to smartphone well-off netizens, only $51 \%$ of reluctant smartphone essentialists are males, $13 \%$ have obtained a high educational level, $24 \%$ are active in the labor market, and $48 \%$ have worked in high-skill occupations. About two out of three (67\%) report having good or very good health status. Again, all these percentages are significantly lower than among smartphone well-off netizens.

\section{Discussion}

\section{Segmentation model findings and implications}

Drawing on the integration of the behavioral and benefit segmentation technique, the two research questions of this study aimed to investigate whether distinctive customer groups of older adults exist in the mobile phone market. The findings indicate that, indeed, there are two different clusters of older adults within each of the five a priori defined segments of the mobile phone market. Besides providing detailed profiles for each of the identified clusters, the integrated behavioral and benefit segmentation model has also unveiled a number of relevant insights that add to the understanding of existing segmentation models discussed earlier in this paper.

First, it has confirmed that older adults in the mobile phone market, like older consumers in general, are not a homogenous group in terms of behavioral patterns and benefits. The 10 identified clusters confirm the suggestions of many scholars (e.g., Bone Fitzgerald, 1991; Moschis, 1991; Sudbury \& Simcock, 2009) that no other consumer market 
justifies segmentation more than that of older consumers, because, with different life-course trajectories, people in later life become increasingly dissimilar with respect to lifestyles, needs, perceived and experienced product benefits, and consumption behavior. This study shows that such differences among older adults are particularly reflected in their (non-)use of mobile phones. In order for marketing researchers and marketers to take advantage of this diversity, segmentation studies of this market should not be based on samples of the general population but rather on samples of older adults.

Second, the results reveal that older mobile phone users are not necessarily members of "basic" and "conservative" segments who use only the most simple and voice-based features of mobile phones, as frequently argued in the literature. Instead, as Lee (2007) and Vincente and Lopes (2016) suggest, among older mobile phone users, there are clusters of consumers with high-end devices who use advanced mobile phone features and have a clear perception of their benefits that are based on their user experience. For example, in this study, clusters such as frugal callers and old-fashioned quitters who are characterized by the most basic usage patterns represent only two of the six groups in the segment of feature phone users. Moreover, clusters such as active socializing onliners and privacy-struck savvy eagers suggest that older adults do not use only coordination and entertainment features (e.g., alarm clock, calendar, reminders, listening to music) on feature phones but also internet-based services for email exchange, web browsing, and/or online social networking.

Thus, our third observation is related to the use of mobile internet as one of the market drivers for the deployment and adoption of smartphone services that can play a major role in enhancing older adults' well-being and quality of life (Navabi, Ghaffari, \& Jannat-Alipoor, 2016; Plaza et al., 2011). Our findings sustain the need to overcome the stereotypical image of older adults as anxious, averse, and/or disinterested consumers of internet-based mobile services. They confirm prior research showing mobile internet as an increasingly important 
aspect of mobile phone consumption among older adults (Mohadisdudis \& Ali, 2014; Seifert \& Schelling, 2015; Vicente \& Lopes, 2016). However, it seems that feature phone users of mobile internet do not perceive internet access on smartphones as beneficial enough to convert. Addressing this issue with an effective marketing strategy appears to be a complex challenge, because different feature phone users of mobile internet express a wide array of socio-technical barriers pertaining to material, attitudinal, cognitive, and/or motivational factors that inhibit the potential of associated benefits. For instance, privacy-struck savvy eagers are inhibited by privacy concerns, and informed safeplayers do not feel that a smartphone is something they would need, while active socializing onliners do not know almost anything about smartphones. Hence, marketing strategies meant to aid the transition to a smartphone for first-time buyers/users should be nuanced and targeted enough to tap the specific aspects of reluctance among older feature phone users. Consecutively, they should also be able to put forward a diversified array of benefits of smartphone features according to the different user experience and values associated with feature phones. For instance, for labor active older adults smartphone campaigns could promote services for improved effectiveness, coordination, and time management, whereas for older adults with chronic diseases the leverage could be the facilitation of medical adherence, documenting health needs and measures, and participation in and exchange of peer support. To use the words of Vincente and Lopes (2016), the "one model fits all” approach would very likely be of little value and inadequate to reach new smartphone users among older adults. For this purpose segmentation models could be also used to create personas (Pruitt \& Adlin, 2005) as data-driven and realistic representations of older adults segments in the mobile phone market that might aid in designing and marketing age-friendly mobile phone services across different domains of their everyday life such as health and social care. 
Fourth, although their digital skills are improving, and older adults are becoming a more important consumer segment of internet-based services on mobile devices (Kuoppamäki, Taipale, \& Wilska, 2017), this does not necessary imply that they will fully exploit technological affordances of smartphones. In this sense, our findings corroborate what other scholars (e.g., Berenguer et al., 2017; Sell et al., 2014) have suggested when arguing that smartphone ownership does not always translate into the actual use of advanced services such as mobile internet and applications. In fact, Zhou et al. (2013) confirm that mechanisms and factors which contribute to the acceptance of smartphones as products do not necessary overlap with predictors of new smartphone-based functions. In this study, for instance, we found that in the smartphone user segment, smartphone well-off netizens and reluctant smartphone essentialists are characterized by two very distinctive benefit and behavioral user profiles. On one hand, the former have embraced the social and technological affordances of a smartphone to the extent that it has become a firm part of their work and family life. On the other hand, the latter still perceive and use it primarily as a feature phone - for calling and texting without going online. Interestingly, these results resonate with both the existing segmentation models of older feature phone users (cf., Lee, 2007; Vicente \& Lopes, 2016) as well as with the findings of mature mobile research in general, which, for example, found that one out of four smartphone users over the age of 55 has never downloaded a mobile application to their smartphone and that more than two-thirds of older adults in the same age group do not use their smartphone for social networking (Deloitte, 2014). Although the gap in smartphone ownership among older adults will very likely narrow and disappear over the coming years - as feature phones will not be available on the market anymore (Berenguer et al., 2017) - the differences in usage and consumption styles will very likely persist in the future. Hence, it seems that acceptance factors of mobile internet and specific features shall 
constitute a focal point for marketers in the benefit segmentation and understanding of this market.

Lastly, this study revealed that even though all clusters show some similarities, they can be also identified by notable differences in terms of socio-demographic and life-course characteristics. When the five segments of mobile phone (non-)users are compared across the segmentation descriptors, it appears that, within different segments, there is an observable variability of significant descriptors. This would indicate that segmentation models in this market should encompass a wide array of demographic and life-course characteristics of older adults, because not all have comparable discrimination value within different segments. Nevertheless, there are a few descriptors with more discrimination value. In particular, significant differences based on educational attainment, occupational status, and household income were observed within four segments, whereas health status had significant implications within three segments. It is interesting that all these variables, with the exception of education, were ascertained as key segmentation criteria in the mature market in general (Bone Fitzgerald, 1991). It seems that, even though mobile phones are a product-specific category, relying on some general mature market segmentation criteria might provide researchers with a good starting point for the development of more detailed segmentation models to approach older adults in the mobile phone market. In addition, age and gender did not show up as important predictors in the segmentation. Notably, the only gendered segment consisted of smartphone users, with a higher percentage of females among the reluctant smartphone essentialists. Conversely, the only age-dependent segment included the mobile phone non-users, where the largest percentage of non-users over the age of 75 was found among the resigned stragglers. Contrary to expectations, the two clusters of mobile phone non-users were also distinctive regarding their computer and internet use. In fact, these two descriptors were shown to be capable of discriminating clusters in all the other four segments. 
In sum, when looking at the segmentation model developed herein, we can conclude that the demographic and life-course descriptors show adequate practical value to be utilized in a reallife setting, because the resulting clusters are measurable, accessible, substantial, and differentiable.

\section{Limitations of the study and future research}

However, the segmentation model presented in this study is bound by a couple of limitations that demand further attention. In particular, the country-specific sample and the limited set of segmentation descriptors should be addressed. While Slovenia is an average-performing EU member state in terms of many adoption benchmarks related to mobile phones and other information and communication technologies (ICTs), older adults in Slovenia have specific socio-economic characteristics that might reduce the cross-cultural generalizability of the results (Petrovčič et al., 2016). For instance, when compared to older adults living in OECD countries, older adults in Slovenia have a lower disposable income and are exposed to a bigger poverty inequality between young and old older adults (OECD, 2013). They are also and more likely to live in three-generation households when compared with their peers in other EU member states (Petrovčič et al., 2016). Moreover, future research should consider using a wider array of criteria shown to be valuable for the segmentation of mature markets, such as measures of lifestyle, (new) media consumption, buying style, consumer venturesomeness, market mavenism, psychographics, and similar (e.g., Bone Fitzgerald, 1991; Moschis, 2003; Sudbury \& Simcock, 2009). Another potential extension of the current segmentation descriptors would be to examine whether the impact of age identity (Cavan, Burgess, Havinghurst, \& Goldhamer, 1949) and cognitive age (Barak \& Schiffman, 1981) differs from the impact of chronological age. Of course, adding new measures and blocks of scales increases the questionnaire length, causing a higher respondent burden, which, in telephone surveys of older adults, might negatively affect the response quality. In this context, 
an alternative for reducing the respondent burden would be to replace the survey self-reports of communication service/equipment use behaviors with objective system-captured measures of the use (intensity) of (mobile) telecommunication services and devices. As literature indicates that retrospective self-reports share little variance with objective system-captured measures, this would very likely also improve the validity of their measurements of various service/equipment use variables (e.g., Abeele, Beullens, \& Roe, 2013; Berolo, Steenstra, Amick III, \& Wells, 2015). Finally, the results, though adequate in answering the two research questions, should be interpreted with caution. The fact that the significant segment descriptors of clusters were determined with bivariate analysis certainly promotes the need for further study of potential interactions and cofounding effects between them. Building a multivariate model with descriptors as predictors and cluster membership as a dependent variable would be a sound approach. However, we chose bivariate analysis due to its relatively well-established and intuitive approach in segmentation studies and because of our restrictions in the sample size of segments.

\section{Conclusion}

With the behavioral and benefit segmentation model developed in this study, we have indicated that older adults are not a homogeneous consumer group in the mobile phone market, but rather that they can be clustered in heterogeneous segments of mobile phone (non-)users with distinguishable demographic and life-course properties. The available behavioral criteria such as frequency of mobile phone use, type of service-plan, and in particular, use of mobile phone features as well as actual and perceived benefits associated with mobile phone acceptance factors and barriers have demonstrated their usefulness in demarking the 10 profiles of older mobile phone (non-)users. Moreover, educational attainment, occupational status, health status, and household income have been confirmed as segment descriptors with good discrimination value across segments also in this product- 
specific category of the mature market. In substantive terms, the results account for a mounting role of mobile internet amongst older adults that, however, has not yet become a sufficient incentive for many feature phone users to take up smartphones. Likewise, a number of older smartphone users only showed limited interest in or scarcely recognized the benefits of advanced smartphone services such as mobile applications. Finding effective marketing strategies for these two challenges and addressing subgroups of feature phone and smartphone users accordingly will very likely open new opportunities for the development of the mobile phone market in general. In fact, these are clusters that are expected to become a prime target for a range of the most innovative and advanced ICT-based products, spanning from media and entertainment services to complex ambient assistive living solutions.

\section{Acknowledgements}

The authors would like to recognize and thank Jernej Berzelak and Gašper Stanovnik for their valuable assistance and advice in the survey data collection process.

\section{Funding}

This work was supported by the Slovenian Research Agency [grant number L5-6818].

\section{References}

AAPOR. (2016). Standard Definitions: Final Dispositions of Case Codes and Outcome Rates for Surveys, 9th edition. AAPOR. Retrieved from http://www.aapor.org/AAPOR_Main/media/publications/StandardDefinitions20169theditionfinal.pdf

Aarnio, A., Enkenberg, A., Heikkila, J., \& Hirvola, S. (2002). Adoption and use of mobile services. Empirical evidence from a Finnish survey. In Proceedings of the 35th Annual Hawaii International Conference on System Sciences (pp. 1454-1463). https://doi.org/10.1109/HICSS.2002.994013 
Abeele, M. V., Beullens, K., \& Roe, K. (2013). Measuring mobile phone use: Gender, age and real usage level in relation to the accuracy and validity of self-reported mobile phone use. Mobile Media \& Communication, 1(2), 213-236. https://doi.org/10.1177/2050157913477095

Ahmad, R. (2003). Benefit segmentation: A potentially useful technique of segmenting and targeting older consumers. International Journal of Market Research, 45(3), 373-388.

Anckar, B., \& D'Incau, D. (2002). Value creation in mobile commerce: Findings from a consumer survey. Journal of Information Technology Theory and Application, 4(1), 43-64.

Barak, B., \& Schiffman, L. G. (1981). Cognitive Age: A Nonchronological Age Variable. Advances in Consumer Research, 8(1), 602-606.

Berenguer, A., Goncalves, J., Hosio, S., Ferreira, D., Anagnostopoulos, T., \& Kostakos, V. (2017). Are Smartphones Ubiquitous?: An in-depth survey of smartphone adoption by seniors. IEEE Consumer Electronics Magazine, 6(1), 104-110. https://doi.org/10.1109/MCE.2016.2614524

Berolo, S., Steenstra, I., Amick III, B. C., \& Wells, R. P. (2015). A Comparison of Two Methods to Assess the Usage of Mobile Hand-Held Communication Devices. Journal of Occupational and Environmental Hygiene, 12(4), 276-285. https://doi.org/10.1080/15459624.2014.973111

Bone Fitzgerald, P. (1991). Identifying mature segments. Journal of Consumer Marketing, 8(4), 19-32. https://doi.org/10.1108/07363769110035126

Cavan, R. S., Burgess, E. W., Havinghurst, R. J., \& Goldhamer, H. H. (1949). Personal Adjustment in Old Age. Chicago: Science Research Associates.

Chen, A. N., McGaughey, R. E., Zeltmann, S. M., Lu, H.-K., \& Lee, M. R. (2017). How Seniors in Taiwan Use Information Technology: Computer and Cell Phones. 
International Journal of Human-Computer Interaction.

https://doi.org/10.1080/10447318.2017.1335445

Chen, K., Chan, A. H. S., \& Tsang, S. N. H. (2013). Usage of mobile phones amongst elderly people in Hong Kong. Proceedings of the International MultiConference of Engineers and Computer Scientists 2013, (Vol II), 1016-1019.

Chiu, T., Fang, D., Chen, J., Wang, Y., \& Jeris, C. (2001). A Robust and Scalable Clustering Algorithm for Mixed Type Attributes in Large Database Environment. In Proceedings of the Seventh ACM SIGKDD International Conference on Knowledge Discovery and Data Mining (pp. 263-268). New York, NY, USA: ACM. https://doi.org/10.1145/502512.502549

Choudrie, J., Pheeraphuttharangkoon, S., Zamani, E., \& Giaglis, G. (2014). Investigating the adoption and use of smartphones in the UK: A silver-surfers perspective (Working paper) (pp. 1-19). University of Hertfordshire. Retrieved from http://uhra.herts.ac.uk/handle/2299/13507

Chung, B. D., Park, J. H., Koh, Y. J., \& Lee, S. (2016). User Satisfaction and Retention of Mobile Telecommunications Services in Korea. International Journal of HumanComputer Interaction, 32(7), 532-543. https://doi.org/10.1080/10447318.2016.1179083

Conci, M., Pianesi, F., \& Zancanaro, M. (2009). Useful, Social and Enjoyable: Mobile Phone Adoption by Older People. In Proceedings of the 12th IFIP TC 13 International Conference on Human-Computer Interaction: Part I (pp. 63-76). Berlin, Heidelberg: Springer-Verlag. https://doi.org/10.1007/978-3-642-03655-2_7

Constantiou, I. D., Papazafeiropoulou, A., \& Vendelø, M. T. (2009). Does Culture Affect the Adoption of Advanced Mobile Services? A Comparative Study of Young Adults' 
Perceptions in Denmark and the UK. SIGMIS Database, 40(4), 132-147. https://doi.org/10.1145/1644953.1644962

Deloitte. (2014). The smartphone generation gap: Over-55? There's no app for that. London: Deloitte. Retrieved from https://www2.deloitte.com/content/dam/Deloitte/au/Documents/technology-mediatelecommunications/deloitte-au-tmt-smartphone-generation-gap-011014.pdf

Deng, Z., Mo, X., \& Liu, S. (2014). Comparison of the middle-aged and older users' adoption of mobile health services in China. International Journal of Medical Informatics, 83(3), 210-224. https://doi.org/10.1016/j.ijmedinf.2013.12.002

European Commission. (2016). Eurobarometer 84.4 (2015). TNS opinion, Brussels [Producer]. GESIS Data Archive, Cologne. ZA6644 Data file Version 2.0.0. European Union. Retrieved from https://dbk.gesis.org/

Gerpott, T. J., Thomas, S., \& Weichert, M. (2013). Characteristics and mobile Internet use intensity of consumers with different types of advanced handsets: An exploratory empirical study of iPhone, Android and other web-enabled mobile users in Germany. Telecommunications Policy, 37(4-5), 357-371. https://doi.org/10.1016/j.telpol.2012.04.009

Greenberg, M., \& McDonald, S. S. (1989). Successful Needs/Benefits Segmentation: A User's Guide. Journal of Consumer Marketing, 6(3). https://doi.org/10.1108/EUM0000000002552

Guo, X., Sun, Y., Wang, N., Peng, Z., \& Yan, Z. (2012). The dark side of elderly acceptance of preventive mobile health services in China. Electronic Markets, 23(1), 49-61. https://doi.org/10.1007/s12525-012-0112-4 
Gurtner, S., Reinhardt, R., \& Soyez, K. (2014). Designing mobile business applications for different age groups. Technological Forecasting and Social Change, 88, 177-188. https://doi.org/10.1016/j.techfore.2014.06.020

Hamka, F., Bouwman, H., de Reuver, M., \& Kroesen, M. (2014). Mobile customer segmentation based on smartphone measurement. Telematics and Informatics, 31(2), 220-227. https://doi.org/10.1016/j.tele.2013.08.006

Hardill, I., \& Olphert, C. W. (2012). Staying connected: Exploring mobile phone use amongst older adults in the UK. Geoforum, 43(6), 1306-1312. https://doi.org/10.1016/j.geoforum.2012.03.016

Haverila, M. J. (2013). Market segmentation in the cell phone market among adolescents and young adults. Asia Pacific Journal of Marketing and Logistics, 25(3), 346-368. https://doi.org/10.1108/APJML-07-2012-0064

Huffman, C., Ratneshwar, S., \& Mick, D. G. (2005). Consumer goal structures and goaldetermination process: An integrative framework. In S. Ratneshwar, D. G. Mick, \& C. Huffman, The Why of Consumption: Contemporary Perspectives on Consumer Motives, Goals, and Desires (pp. 9-35). London, UK: Routledge.

Hur, H. J., Lee, H. K., \& Choo, H. J. (2017). Understanding usage intention in innovative mobile app service: Comparison between millennial and mature consumers. Computers in Human Behavior, 73, 353-361. https://doi.org/10.1016/j.chb.2017.03.051

Kalton, G. (1983). Compensating for Missing Survey Data. Ann Arbor, MI: Institute for Social Research, The University of Michigan.

Kubik, S. (2009). Motivations for cell phone use by older Americans. Gerontechnology, 8(3), 150-164. https://doi.org/10.4017/gt.2009.08.03.007.00 
Kuoppamäki, S.-M., Taipale, S., \& Wilska, T.-A. (2017). The use of mobile technology for online shopping and entertainment among older adults in Finland. Telematics and Informatics, 34(4), 110-117. https://doi.org/10.1016/j.tele.2017.01.005

Kurniawan, S. (2008). Older People and Mobile Phones: A Multi-method Investigation. International Journal of Human Computer Studies, 66(12), 889-901. https://doi.org/10.1016/j.ijhcs.2008.03.002

Lee, J. H., \& Kim, J. (2014). Socio-demographic gaps in mobile use, causes, and consequences: a multi-group analysis of the mobile divide model. Information, Communication \& Society, 17(8), 917-936. https://doi.org/10.1080/1369118X.2013.860182

Lee, Y. S. (2007, September 3). Older adults user experiences with mobile phones: Identification of user clusters and user requirements (Doctoral Disseration). Virginia Tech, Blacksburg, VA. Retrieved from https://vtechworks.lib.vt.edu/handle/10919/29003

Mazzoni, C., Castaldi, L., \& Addeo, F. (2007). Consumer behavior in the Italian mobile telecommunication market. Telecommunications Policy, 31(10-11), 632-647. https://doi.org/10.1016/j.telpol.2007.07.009

Mohadisdudis, H. M., \& Ali, N. M. (2014). A study of smartphone usage and barriers among the elderly. In 2014 3rd International Conference on User Science and Engineering ( $i$ USEr) (pp. 109-114). https://doi.org/10.1109/IUSER.2014.7002686

Moschis, G. P. (1991). Marketing to older adults. Journal of Consumer Marketing, 8(4), 3341. https://doi.org/10.1108/07363769110035135

Moschis, G. P. (2003). Marketing to older adults: An updated overview of present knowledge and practice. Journal of Consumer Marketing, 20(6), 516-525. https://doi.org/10.1108/07363760310499093 
Navabi, N., Ghaffari, F., \& Jannat-Alipoor, Z. (2016). Older adults' attitudes and barriers toward the use of mobile phones. Clinical Interventions in Aging, 11, 1371-1378. https://doi.org/10.2147/CIA.S112893

Niemelä-Nyrhinen, J. (2007). Baby boom consumers and technology: Shooting down stereotypes. Journal of Consumer Marketing, 24(5), 305-312. https://doi.org/10.1108/07363760710773120

OECD. (2013). Pensions at a Glance 2013. OECD Publishing. https://doi.org/10.1787/pension_glance-2013-en

Ofcom. (2016). Adults' media use and attitudes. London: Ofcom. Retrieved from https://www.ofcom.org.uk/_data/assets/pdf_file/0026/80828/2016-adults-media-useand-attitudes.pdf

Okazaki, S. (2006). What do we know about mobile Internet adopters? A cluster analysis. Information \& Management, 43(2), 127-141. https://doi.org/10.1016/j.im.2005.05.001

Petrovčič, A., Vehovar, V., \& Dolničar, V. (2016). Landline and mobile phone communication in social companionship networks of older adults: An empirical investigation in Slovenia. Technology in Society, 45, 91-102. https://doi.org/10.1016/j.techsoc.2016.02.007

Plaza, I., Martín, L., Martin, S., \& Medrano, C. (2011). Mobile Applications in an Aging Society: Status and Trends. Journal of Systems and Software, 84(11), 1977-1988. https://doi.org/10.1016/j.jss.2011.05.035

Pruitt, J., \& Adlin, T. (2005). The Persona Lifecycle: Keeping People in Mind Throughout Product Design. San Francisco, CA: Morgan Kaufmann.

Renaud, K., \& van Biljon, J. (2008). Predicting Technology Acceptance and Adoption by the Elderly: A Qualitative Study. In Proceedings of the 2008 Annual Research Conference of the South African Institute of Computer Scientists and Information Technologists on 
IT Research in Developing Countries: Riding the Wave of Technology (pp. 210-219).

New York, NY, USA: ACM. https://doi.org/10.1145/1456659.1456684

Roque, N. A., \& Boot, W. R. (2016). A New Tool for Assessing Mobile Device Proficiency in Older Adults: The Mobile Device Proficiency Questionnaire. Journal of Applied Gerontology, 0733464816642582. https://doi.org/10.1177/0733464816642582

Seifert, A., \& Schelling, H. R. (2015). Mobile use of the Internet using smartphones or tablets by Swiss people over 65 years. Gerontechnology, 14(1), 57-62. https://doi.org/10.4017/gt.2015.14.1.006.00

Sell, A., Mezei, J., \& Walden, P. (2014). An attitude-based latent class segmentation analysis of mobile phone users. Telematics and Informatics, 31(2), 209-219. https://doi.org/10.1016/j.tele.2013.08.004

Sell, A., Walden, P., \& Carlsson, C. (2010a). An Exploratory Three Year Segmentation of Finnish Mobile Service Users. In M. Rosemann \& P. Green (Eds.), ACIS 2010 Proceedings (p. Paper 85). AIS Electronic Library.

Sell, A., Walden, P., \& Carlsson, C. (2010b). Are you Efficient, Trendy or Skilful? An exploratory segmentation of mobile service users. In G. M. Giaglis \& V. Zwass (Eds.), Ninth International Conference on Mobile Business and Ninth Global Mobility Roundtable (ICMB-GMR) (pp. 116-123). IEEE Computer Society.

Smith, A. (2015). U.S. Smartphone Use in 2015. Washington, DC: Pew Research Center. Retrieved from http://www.pewinternet.org/2015/04/01/us-smartphone-use-in-2015/ Sudbury, L., \& Simcock, P. (2009). A multivariate segmentation model of senior consumers. Journal of Consumer Marketing, 26(4), 251-262. https://doi.org/10.1108/07363760910965855

van Dijk, J. A. G. M. (2006). Digital divide research, achievements and shortcomings. Poetics, 34(4), 221-235. https://doi.org/10.1016/j.poetic.2006.05.004 
Venkatesh, V., Morris, M. G., Davis, G. B., \& Davis, F. D. (2003). User Acceptance of Information Technology: Toward a Unified View. MIS Q., 27(3), 425-478.

Verkasalo, H., López-Nicolás, C., Molina-Castillo, F. J., \& Bouwman, H. (2010). Analysis of Users and Non-users of Smartphone Applications. Telematics and Informatics, 27(3), 242-255. https://doi.org/10.1016/j.tele.2009.11.001

Vicente, P., \& Lopes, I. (2016). Attitudes of older mobile phone users towards mobile phones. Communications, 41(1), 71-86. https://doi.org/10.1515/commun-2015-0026

Wang, L., Rau, P. L. P., \& Salvendy, G. (2011). Older Adults’ Acceptance of Information Technology. Educational Gerontology, 37(12), 1081-1099. https://doi.org/10.1080/03601277.2010.500588

Wind, Y. (1978). Issues and Advances in Segmentation Research. Journal of Marketing Research, 15(3), 317-337. https://doi.org/10.2307/3150580

Xue, L., Yen, C. C., Chang, L., Chan, H. C., Tai, B. C., Tan, S. B., ... Choolani, M. (2012). An exploratory study of ageing women's perception on access to health informatics via a mobile phone-based intervention. International Journal of Medical Informatics, 81(9), 637-648. https://doi.org/10.1016/j.ijmedinf.2012.04.008

Zhou, J., Rau, P. L. P., \& Salvendy, G. (2013). Older adults' use of smart phones: an investigation of the factors influencing the acceptance of new functions. Behaviour \& Information Technology, 33(6), 552-560.

https://doi.org/10.1080/0144929X.2013.780637 


\section{Tables}

Table 1. Socio-demographic characteristics of the realized sample

\begin{tabular}{|c|c|c|c|}
\hline Variable & Categories & $\mathrm{N}^{\mathrm{a}}$ & $\%^{\mathrm{b}}$ \\
\hline \multirow[t]{2}{*}{ Gender } & Male & 1581 & 45 \\
\hline & Female & & 55 \\
\hline \multirow[t]{4}{*}{ Age (years) } & $55-64$ & 1581 & 44 \\
\hline & $65-74$ & & 30 \\
\hline & $75-84$ & & 20 \\
\hline & 85 or more & & 7 \\
\hline \multirow[t]{3}{*}{ Education } & Vocational or lower & 1541 & 41 \\
\hline & High school & & 44 \\
\hline & College or university & & 15 \\
\hline \multirow[t]{2}{*}{ Labour status } & Active (working) & 1581 & 15 \\
\hline & Not active (retired) & & 85 \\
\hline \multirow[t]{2}{*}{ Occupation } & High skill & 1459 & 45 \\
\hline & Low skill & & 55 \\
\hline \multirow[t]{3}{*}{ Marital status } & Married or cohabiting & 1537 & 72 \\
\hline & Single & & 8 \\
\hline & Widowed & & 20 \\
\hline \multirow[t]{2}{*}{ Having children } & Yes & 1537 & 92 \\
\hline & No & & 8 \\
\hline \multirow[t]{5}{*}{ Household size } & 1 & 1532 & 20 \\
\hline & 2 & & 46 \\
\hline & 3 & & 16 \\
\hline & 4 & & 9 \\
\hline & 5 or more & & 9 \\
\hline \multirow[t]{2}{*}{ Household structure } & One generation & 1502 & 63 \\
\hline & Multiple generation & & 37 \\
\hline \multirow[t]{2}{*}{ Household income } & Up to $1.300 €$ & 1454 & 51 \\
\hline & $1.300 €$ or more & & 49 \\
\hline \multirow[t]{5}{*}{ Living area (inhabitants) } & Up to 500 & 1525 & 29 \\
\hline & $501-2,000$ & & 22 \\
\hline & $2,001-10,000$ & & 18 \\
\hline & $10,001-50,000$ & & 14 \\
\hline & 50,000 or more & & 18 \\
\hline \multirow[t]{3}{*}{ Region } & East Slovenia & 1581 & 51 \\
\hline & Central Slovenia & & 24 \\
\hline & West Slovenia & & 24 \\
\hline
\end{tabular}

Note: ${ }^{a}$ Sample size varies due to non-responses and non-applicability of questions. ${ }^{b}$ Percentages may not always sum to 100 due to rounding. 
Table 2. Information and communication technology adoption amongst older adults in the realized sample

\begin{tabular}{|c|c|c|c|}
\hline Variable & Categories & $\mathrm{N}^{\mathrm{a}}$ & $\%^{\mathrm{b}}$ \\
\hline \multirow[t]{2}{*}{ Household landline access } & Yes & 1581 & 97 \\
\hline & No & & 3 \\
\hline \multirow[t]{2}{*}{ Landline use at home } & Yes & 1536 & 98 \\
\hline & No & & 2 \\
\hline \multirow[t]{2}{*}{ Mobile phone use } & Yes & 1581 & 90 \\
\hline & No & & 10 \\
\hline \multirow[t]{2}{*}{ Smartphone acquaintance } & Heard about smartphones & 1565 & 82 \\
\hline & Not heard about smartphones & & 18 \\
\hline \multirow[t]{5}{*}{ Smartphone familiarity } & Very low & 1233 & 39 \\
\hline & Low & & 19 \\
\hline & Average & & 21 \\
\hline & High & & 15 \\
\hline & Very high & & 6 \\
\hline \multirow[t]{2}{*}{ Smartphone use } & Yes (smartphone users) & 1413 & 27 \\
\hline & No (feature phone users) & & 73 \\
\hline \multirow[t]{2}{*}{ Mobile phone ownership } & Yes & 1415 & 93 \\
\hline & No & & 7 \\
\hline \multirow[t]{2}{*}{ New mobile device } & Yes & 1318 & 92 \\
\hline & No & & 8 \\
\hline \multirow[t]{2}{*}{ Service plan } & Pre-paid subscribers & 1407 & 22 \\
\hline & Post-paid subscribers & & 78 \\
\hline \multirow[t]{5}{*}{ Mobile phone age } & Up to 1 year & 1405 & 23 \\
\hline & $1-2$ years & & 25 \\
\hline & $2-3$ years & & 14 \\
\hline & $3-4$ years & & 10 \\
\hline & 4 years or more & & 28 \\
\hline \multirow[t]{2}{*}{ Mobile phone use frequency } & Daily & 1405 & 84 \\
\hline & Less often than daily & & 16 \\
\hline \multirow[t]{2}{*}{ Regular computer use } & Yes & 1555 & 53 \\
\hline & No & & 47 \\
\hline \multirow[t]{2}{*}{ Daily computer use } & Yes & 763 & 75 \\
\hline & No & & 25 \\
\hline \multirow[t]{2}{*}{ Regular internet use } & Yes & 1566 & 51 \\
\hline & No & & 49 \\
\hline \multirow[t]{2}{*}{ Daily internet use } & Yes & 804 & 75 \\
\hline & No & & 25 \\
\hline
\end{tabular}

Note: ${ }^{a}$ Sample size varies due to non-responses and non-applicability of questions. ${ }^{\mathrm{b}}$ Percentages may not always sum to 100 due to rounding. 
Table 3. Profiles of clusters of older adults in the mobile phone market

\begin{tabular}{|c|c|c|c|c|c|c|c|c|c|c|c|c|c|c|c|c|}
\hline Variable / Cluster ${ }^{\mathrm{b}}$ & Author(s) & RS & UO & $\chi^{2}$ & $\mathrm{BPO}$ & $\mathrm{FC}$ & $\chi^{2}$ & OQ & ASO & $\chi^{2}$ & PSE & IS & $\chi^{2}$ & SWN & RSE & $\chi^{2}$ \\
\hline Household landline access (Yes) & Kubik (2009) & - & - & - & - & - & - & - & - & - & - & - & - & - & - & - \\
\hline Landline use at home (Yes) & & - & - & - & 99 & 100 & 1.7 & 99 & 96 & 3.1 & 97 & 99 & 1.5 & 96 & 95 & 0.1 \\
\hline Mobile phone ownership (Yes) & $\begin{array}{c}\text { Constantiou et al. } \\
(2009)\end{array}$ & - & - & - & 91 & 92 & 0.1 & 93 & 98 & $4.2^{*}$ & 93 & 91 & 0.4 & - & - & - \\
\hline New mobile device (Yes) & & - & - & - & - & - & - & - & - & - & - & - & - & 94 & 90 & 1.5 \\
\hline Ex-mobile phone user (Yes) & & 6 & 37 & $19.5 * *$ & - & - & - & - & - & - & - & - & - & - & - & - \\
\hline Mobile phone age (Up to 1 year) ${ }^{\mathrm{a}}$ & Aarnio et al. (2002) & - & - & - & 7 & 14 & $9.42 *$ & 8 & 18 & $22.3^{* * *}$ & 18 & 11 & $10.1 *$ & 47 & 46 & 4.9 \\
\hline Mobile phone use frequency (Daily) & & - & - & - & 90 & 67 & $13.0 * *$ & 62 & 97 & $\mathbf{5 3 . 5 * *}$ & 100 & 76 & $31.0 * *$ & 98 & 95 & 1.3 \\
\hline Mobile phone carrier (Telekom) ${ }^{\mathrm{a}}$ & Lee (2007) & - & - & - & 53 & 54 & 0.3 & 57 & 55 & 1.2 & 62 & 57 & 0.6 & 48 & 47 & 3.6 \\
\hline Service plan (Post-paid subscribers) & Kubik (2009) & - & - & - & 79 & 53 & $12.7 * *$ & 55 & 90 & $46.5 * *$ & 79 & 81 & 0.1 & 97 & 84 & $15.7 * *$ \\
\hline $\begin{array}{l}\text { Mobile phone monthly expenses } \\
(\text { Up to } 10 €)^{a}\end{array}$ & Aarnio et al. (2002) & - & - & - & - & - & - & - & - & - & - & - & - & 12 & 37 & $32.2 * *$ \\
\hline Heard about smartphones (Yes) & & 7 & 80 & $74.1 * *$ & - & - & - & - & - & - & - & - & - & - & - & - \\
\hline Time & & - & - & - & 86 & 55 & $18.8^{* * *}$ & 73 & 94 & $23.9 * *$ & 97 & 75 & $22.7 * *$ & 99 & 98 & 0.5 \\
\hline Text messaging & & - & - & - & 92 & 3 & $139.6 * *$ & 39 & 90 & $87.2 * *$ & 98 & 61 & $48.6 * *$ & 99 & 90 & $14.2 * *$ \\
\hline Photo camera & & - & - & - & 50 & 3 & $53.1 * *$ & 11 & 74 & $130.6 * *$ & 85 & 42 & $45.7 * *$ & 100 & 85 & $24.2 * *$ \\
\hline Calendar & & - & - & - & 27 & 6 & $14.2 * *$ & 5 & 47 & $74.7 * *$ & 65 & 19 & $47.5^{* * *}$ & 83 & 47 & $41.4 * *$ \\
\hline Alarm clock & & - & - & - & 30 & 0 & $35.1 * *$ & 8 & 42 & $49.6 * *$ & 66 & 22 & $45.2 * *$ & 75 & 58 & $9.3 * *$ \\
\hline Flashlight & Kubik (2009), & - & - & - & 13 & 9 & 0.6 & 11 & 24 & $9.1 * *$ & 41 & 25 & $6.7 * *$ & 59 & 33 & $18.9 * *$ \\
\hline E-mail & $\begin{array}{l}\text { Choudrie et al. } \\
\text { (2014), }\end{array}$ & - & - & - & 4 & 0 & 4.8 & 0 & 5 & $11.3 * *$ & 12 & 5 & $3.3^{*}$ & 83 & 12 & $143.7 * *$ \\
\hline Browsing the web & Hamka et al. (2014) & - & - & - & 3 & 0 & 4.4 & 0 & 4 & 8.1* & 9 & 1 & $7.2^{* * *}$ & 90 & 11 & $177.3^{* * *}$ \\
\hline Maps and navigation & & - & - & - & 3 & 0 & 3.4 & 0 & 2 & 3.6 & 8 & 1 & $7.5^{* *}$ & 62 & 10 & $79.6 * *$ \\
\hline Listening to the music, radio & & - & - & - & 5 & 0 & $6.7 *$ & 1 & 6 & $8.2 *$ & 11 & 1 & $9.1 * *$ & 31 & 9 & $21.0 * *$ \\
\hline Internet television & & - & - & - & 3 & 0 & 3.2 & 0 & 1 & 1.6 & 4 & 0 & 5.5 & 45 & 2 & $64.7 * *$ \\
\hline Online social networks & & - & - & - & 0 & 0 & - & 0 & 2 & 3.2 & 3 & 0 & 3.8 & 40 & 0 & $62.4 * *$ \\
\hline Playing games & & - & - & - & 4 & 0 & 5.4 & 1 & 0 & 1.4 & 1 & 4 & 2.2 & 11 & 3 & 6.0* \\
\hline
\end{tabular}

Note: ${ }^{a}$ Due to space limitations for multinomial variables the obtained value of chi-square test with the percentages for only one (the most representative across all clusters) category is shown. ${ }^{\mathrm{b}}$

The likelihood ratio chi-square statistics is reported in cases when cells have expected counts less than 5 . All values are reported in percentages $(\%)$. ** $\mathrm{p}<.01 ; * \mathrm{p}<.05$. “-” indicates that a

variable was not included in the segmentation model. Cluster names: RS - Resigned stragglers, UO - Uninterested opt-outers, BPO - Better-off phone offliners, FC - Frugal callers, OQ - Old- 
fashioned quitters, ASO - Active socializing onliners, PSE - Privacy-struck savvy eagers, IS - Informed safeplayers, SWN - Smartphone well-off netizens, RSE - Resigned smartphone essentialists. 
Table 3. Continued...

\begin{tabular}{|c|c|c|c|c|c|c|c|c|c|c|c|c|c|c|c|c|}
\hline Variable / Cluster & Author(s) & $\mathrm{RS}$ & UO & $\mathrm{t}$ & $\mathrm{BPO}$ & $\mathrm{FC}$ & $\mathrm{t}$ & OQ & ASO & $\mathrm{t}$ & PSE & IS & $\mathrm{t}$ & SWN & RSE & $\mathrm{t}$ \\
\hline Behavioral intention to use & Gurtner et al. (2014), & - & - & - & - & - & - & - & - & - & 3.5 & 2.3 & $6.7 * *$ & 4.4 & 3.9 & $4.5 * *$ \\
\hline Facilitating conditions & $\begin{array}{l}\text { Choudrie et al. (2014), } \\
\text { Deng et al. (2014). }\end{array}$ & - & - & - & - & - & - & - & - & - & 4.1 & 3.4 & $5.6^{* * *}$ & 4.4 & 4.0 & $5.5 * *$ \\
\hline Enjoyment & Wang et al. (2011), & - & - & - & - & - & - & - & - & - & 3.3 & 2.5 & $5.3^{* *}$ & 4.1 & 3.5 & $4.6^{* * *}$ \\
\hline Social influence & Verkasalo et al. (2010), & - & - & - & - & - & - & - & - & - & 2.8 & 2.3 & $2.9 * *$ & 3.9 & 3.3 & $4.0^{* *}$ \\
\hline Compatibility & & - & - & - & - & - & - & - & - & - & 3.7 & 2.6 & $6.9 * *$ & 4.5 & 3.9 & $6.0 * *$ \\
\hline Resistance to change & & - & - & - & - & - & - & - & - & - & 2.1 & 2.3 & -1.0 & - & - & - \\
\hline Perceived ease of use & & - & - & - & - & - & - & - & - & - & 3.9 & 3.3 & $5.0 * *$ & 4.2 & 3.6 & $7.0 * *$ \\
\hline Perceived usefulness & & - & - & - & - & - & - & - & - & - & 3.1 & 2.4 & $5.1^{* *}$ & 4.2 & 3.7 & $4.8^{* *}$ \\
\hline Mobile anxiety & & - & - & - & - & - & - & - & - & - & 1.9 & 2.2 & $-2.3 * *$ & 1.7 & 2.0 & $-2.7 * *$ \\
\hline Excessive service costs & Mohadisdudis and Ali (2014) & 3.8 & 2.7 & $4.9 * *$ & - & - & - & 3.7 & 3.3 & $2.6^{* *}$ & 2.8 & 3.4 & $-3.2 * *$ & - & - & - \\
\hline Don't know how to use it & & 3.7 & 2.5 & $5.1 * *$ & - & - & - & - & - & - & - & - & - & - & - & - \\
\hline Feel too old & & 3.6 & 2.6 & $4.4 * *$ & - & - & - & 4.0 & 3.5 & $3.1 * *$ & 2.8 & 3.6 & $-4.1 * *$ & - & - & - \\
\hline Phone limited my freedom & & 3.4 & 2.5 & $3.6^{* * *}$ & - & - & - & 3.7 & 3.3 & $2.7 * *$ & 2.3 & 3.1 & $-4.4 * *$ & - & - & - \\
\hline Don't have a real need & & 4.1 & 4.1 & -0.1 & - & - & - & 3.0 & 2.6 & $2.3 * *$ & 1.9 & 3.0 & $-6.1 * *$ & - & - & - \\
\hline Don't want constant availability & & 3.4 & 2.5 & $4.2 * *$ & - & - & - & 2.8 & 2.6 & 1.6 & 2.2 & 2.7 & $-2.8 * *$ & - & - & - \\
\hline Privacy concerns & & 3.3 & 2.5 & $3.7 * *$ & - & - & - & 4.2 & 3.8 & $2.5 * *$ & 3.7 & 4.2 & $-3.2 * *$ & - & - & - \\
\hline Phone radiation & & 3.6 & 2.1 & $7.5^{* *}$ & - & - & - & 2.7 & 2.4 & $2.3 * *$ & 2.1 & 2.6 & $-2.5 * *$ & - & - & - \\
\hline Fear of device damage or loss & & 3.5 & 2.3 & $5.3 * *$ & - & - & - & 3.0 & 2.8 & 1.5 & 2.3 & 2.8 & $-2.3 * *$ & - & - & - \\
\hline Health impairment & & 3.4 & 2.0 & $6.9 * *$ & - & - & - & 2.0 & 2.0 & 0.1 & 1.4 & 1.7 & $-2.1 * *$ & - & - & - \\
\hline
\end{tabular}

Note: All reported values are means. ** $\mathrm{p}<.01 ; * \mathrm{p}<.05$. “-” indicates that a variable was not included in the segmentation model. Cluster names: RS - Resigned stragglers, UO - Uninterested opt-outers, BPO - Better-off phone offliners, FC - Frugal callers, OQ - Old-fashioned quitters, ASO - Active socializing onliners, PSE - Privacy-struck savvy eagers, IS - Informed safeplayers, SWN - Smartphone well-off netizens, RSE - Resigned smartphone essentialists. 
Table 4. Socio-demographic and life course profiles of clusters of older adults in the mobile phone market

\begin{tabular}{|c|c|c|c|c|c|c|c|c|c|c|c|c|c|c|c|c|c|c|}
\hline \multirow{2}{*}{ Variable } & \multirow{2}{*}{ Category } & \multirow[b]{2}{*}{$\mathrm{RS}$} & \multirow[b]{2}{*}{ UO } & \multirow[b]{2}{*}{$\chi^{2}$} & \multirow[b]{2}{*}{$\mathrm{BPO}$} & \multirow[b]{2}{*}{$\mathrm{FC}$} & \multirow[b]{2}{*}{$\chi^{2}$} & \multicolumn{3}{|c|}{ Clusters $^{\mathrm{b}}$} & \multirow[b]{2}{*}{ PSE } & \multirow[b]{2}{*}{ IS } & \multirow[b]{2}{*}{$\chi^{2}$} & \multirow[b]{2}{*}{ SWN } & \multirow[b]{2}{*}{ RSE } & \multicolumn{3}{|c|}{ Total } \\
\hline & & & & & & & & OQ & ASO & $\chi^{2}$ & & & & & & $\chi^{2}$ & $\mathrm{~N}$ & $\%$ \\
\hline Gender & Male & 27 & 39 & 2.3 & 44 & 39 & 0.4 & 46 & 37 & 2.5 & 49 & 50 & 0.0 & 64 & 51 & 4.9* & 1581 & 45 \\
\hline $\mathrm{Age}^{\mathrm{a}}$ & $55-64$ years & 18 & 28 & $15.9 * *$ & 43 & 31 & 7.4 & 31 & 37 & $8.4^{*}$ & 58 & 46 & 3.4 & 71 & 62 & 2.9 & 1581 & 44 \\
\hline Education $^{\mathrm{a}}$ & High & 5 & 4 & 3.2 & 14 & 2 & $14.0 * *$ & 10 & 18 & $17.6 * *$ & 22 & 6 & $19.8 * *$ & 32 & 13 & $27.7 * *$ & 1541 & 15 \\
\hline Labour status & Active (working) & 3 & 6 & 1.1 & 12 & 4 & 4.7 & 5 & 10 & $3.6^{*}$ & 26 & 11 & 8.0** & 41 & 24 & $8.5^{* * *}$ & 1581 & 15 \\
\hline Occupation & High skill & 30 & 25 & 0.3 & 43 & 17 & $13.4 * *$ & 31 & 49 & $9.9 * *$ & 57 & 41 & $6.0^{*}$ & 67 & 48 & $10.4 * *$ & 1459 & 45 \\
\hline Region $^{\mathrm{a}}$ & East Slovenia & 55 & 67 & 1.9 & 46 & 51 & 0.4 & 55 & 44 & $8.3^{*}$ & 44 & 50 & 1.4 & 58 & 52 & 1.1 & 1581 & 51 \\
\hline Living area ${ }^{\mathrm{a}}$ & $\begin{array}{l}\text { Up to } 500 \\
\text { inhabitants }\end{array}$ & 48 & 28 & $11.3^{*}$ & 30 & 43 & 6.3 & 36 & 27 & 7.8 & 29 & 36 & 5.7 & 18 & 17 & 2.9 & 1525 & 29 \\
\hline Household size ${ }^{a}$ & 1 person & 33 & 11 & $9.6 *$ & 17 & 28 & 3.4 & 29 & 22 & 1.9 & 16 & 11 & 2.8 & 9 & 10 & 0.6 & 1532 & 20 \\
\hline $\begin{array}{l}\text { Household } \\
\text { structure }\end{array}$ & One generation & 72 & 56 & $3.6^{*}$ & 72 & 74 & 0.1 & 69 & 72 & 0.3 & 63 & 60 & 0.1 & 49 & 51 & 0.1 & 1502 & 63 \\
\hline Marital status & $\begin{array}{l}\text { Married or } \\
\text { cohabiting }\end{array}$ & 54 & 74 & $11.5 * *$ & 74 & 62 & 3.0 & 63 & 76 & $10.0 *$ & 78 & 81 & 1.3 & 85 & 82 & 0.3 & 1537 & 72 \\
\hline $\begin{array}{l}\text { Household } \\
\text { income }^{\mathrm{a}}\end{array}$ & $2.100 €+$ & 9 & 6 & $10.9 *$ & 9 & 9 & $17.1 * *$ & 6 & 10 & $13.0 *$ & 22 & 8 & $10.0^{*}$ & 32 & 21 & 7.9 & 1454 & 14 \\
\hline Health status & (Very) good & 31 & 45 & 3.0 & 52 & 41 & 1.9 & 48 & 60 & $4.7 *$ & 73 & 52 & $10.2 * *$ & 78 & 67 & $4.3^{*}$ & 1554 & 58 \\
\hline Impairments & Yes & 52 & 31 & $5.9 *$ & 27 & 38 & 2.1 & 30 & 26 & 0.7 & 15 & 25 & 3.4 & 16 & 16 & 0.0 & 1550 & 25 \\
\hline Domestic help ${ }^{\mathrm{a}}$ & Yes & 7 & 5 & 2.6 & 2 & 4 & 3.5 & 4 & 2 & 6.0 & 3 & 4 & $10.0 *$ & 2 & 1 & 1.1 & 1547 & 3 \\
\hline $\begin{array}{l}\text { Regular internet } \\
\text { use }\end{array}$ & Yes & 1 & 13 & $10.1 * *$ & 46 & 10 & $28.9 * *$ & 23 & 56 & $34.7 * *$ & 81 & 50 & $23.4 * *$ & 98 & 80 & $25.5^{* *}$ & 1566 & 51 \\
\hline Daily internet use & Yes & 0 & 33 & 0.4 & 76 & 48 & 2.7 & 49 & 76 & $8.0^{* * *}$ & 74 & 63 & 2.1 & 91 & 81 & $5.0 *$ & 804 & 75 \\
\hline Internet skills & (Very) good & 100 & 61 & 0.5 & 36 & 24 & 0.6 & 30 & 31 & 1.5 & 56 & 33 & $7.3^{*}$ & 78 & 53 & $16.6 * *$ & 800 & 53 \\
\hline $\begin{array}{l}\text { Regular computer } \\
\text { use }\end{array}$ & Yes & 1 & 14 & $10.3 * *$ & 51 & 11 & $33.2 * *$ & 25 & 57 & $32.6 * *$ & 84 & 50 & $29.2 * *$ & 96 & 84 & $12.6 * *$ & 1555 & 53 \\
\hline $\begin{array}{l}\text { Daily computer } \\
\text { use }\end{array}$ & Yes & 0 & 59 & 1.0 & 68 & 53 & 0.9 & 49 & 81 & $13.1 * *$ & 73 & 65 & 1.0 & 88 & 82 & 1.4 & 763 & 75 \\
\hline Total & $\mathrm{N}(\%)$ & $\begin{array}{l}78 \\
(7) \\
\end{array}$ & $\begin{array}{l}57 \\
(5) \\
\end{array}$ & 135 & $75(7)$ & $\begin{array}{l}101 \\
(9)\end{array}$ & 176 & $\begin{array}{r}163 \\
(14) \\
\end{array}$ & $\begin{array}{l}146 \\
(13) \\
\end{array}$ & 309 & $\begin{array}{l}106 \\
(9)\end{array}$ & $117(10)$ & 223 & $\begin{array}{l}168 \\
(15) \\
\end{array}$ & $\begin{array}{l}121 \\
(11) \\
\end{array}$ & 289 & 1132 & 100 \\
\hline
\end{tabular}

selected variable is shown. All values with the exception of sample size ale of chi-square test with the perten in counts less than 5.** $<0.01 ; * \mathrm{p}<0.05$. Cluster names: RS - Resigned stragglers, UO - Uninterested opt-outers, BPO - Better-off phone offliners, FC - Frugal callers, OQ - Old-fashioned quitters, ASO - Active socializing onliners, PSE - Privacy-struck savvy eagers, IS - Informed safeplayers, SWN - Smartphone well-off netizens, RSE - Resigned smartphone essentialists. 


\section{Figure}

Figure 1. The segmentation model of older adults in the mobile phone market in Slovenia

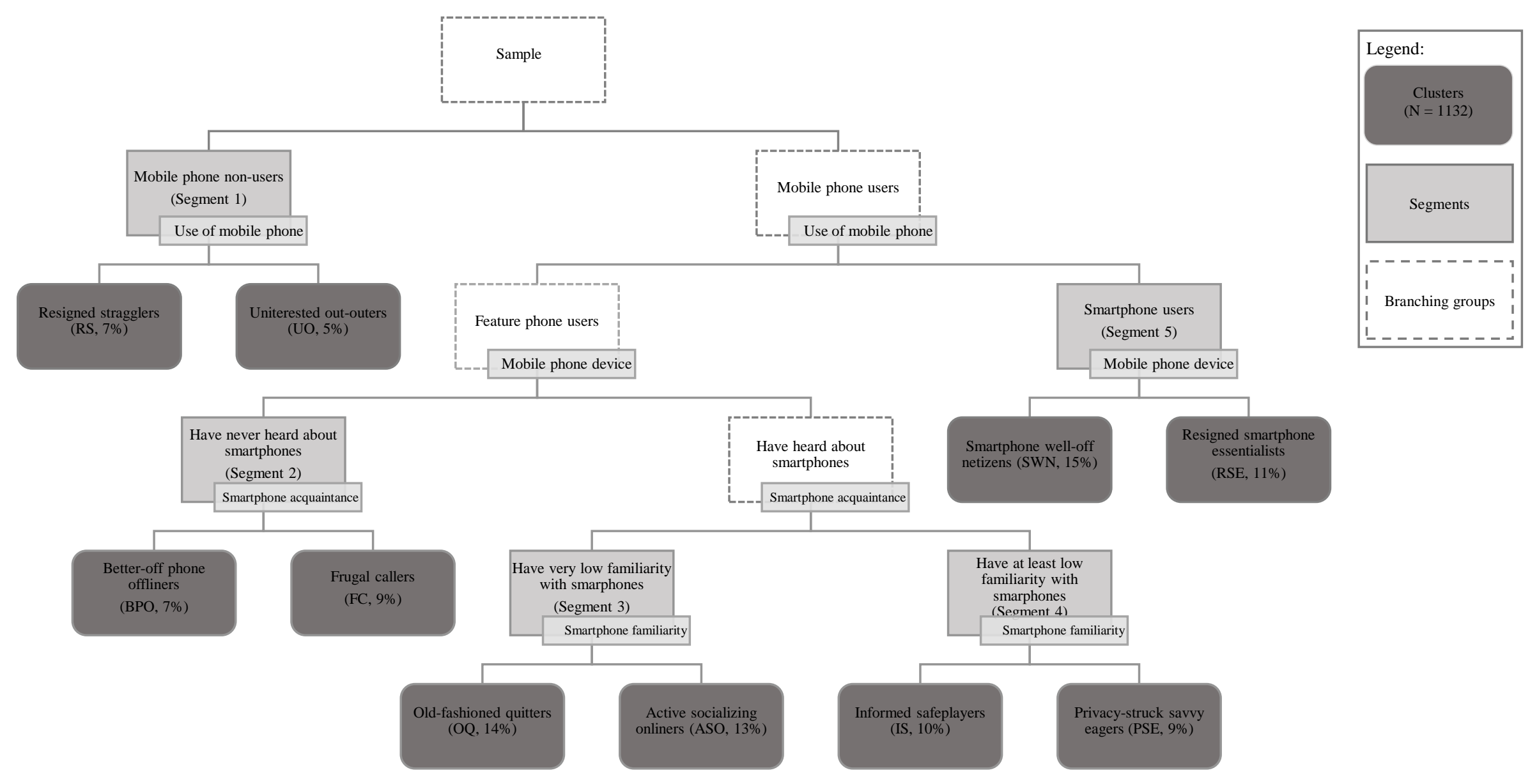

Note: The relative size of clusters is reported with reference to $\mathrm{N}=1132$. 


\section{Appendix}

Table A1. Questionnaire items for rating mobile phone acceptance factors.

\begin{tabular}{|c|c|c|}
\hline Variable & Items for smartphone users & Items for feature phone users \\
\hline \multirow{2}{*}{$\begin{array}{l}\text { Behavioral intention to } \\
\text { use }\end{array}$} & In the next 5 years, I intend to continue using smartphones. & In the next 5 years, I intend to learn how to use smartphone. \\
\hline & $\begin{array}{l}\text { In the next } 5 \text { years, I intend to learn better using smartphones. } \\
\text { In the near future, I intend to use more functions provided by } \\
\text { smartphones. }\end{array}$ & In the next 5 years, I intend to start using smartphone. \\
\hline \multirow[t]{3}{*}{ Facilitating conditions } & I have enough money necessary to use the smartphone. & I would have enough money necessary to use the smartphone. \\
\hline & I have the knowledge necessary to use the smartphone. & I would have the knowledge necessary to use the smartphone. \\
\hline & $\begin{array}{l}\text { A specific person (or group) is available for assistance with } \\
\text { smartphone difficulties. }\end{array}$ & $\begin{array}{l}\text { A specific person (or group) would be available for assistance with } \\
\text { smartphone difficulties. }\end{array}$ \\
\hline \multirow[t]{2}{*}{ Enjoyment } & The actual process of using a smartphone is pleasant. & The actual process of using a smartphone would be pleasant. \\
\hline & I have fun using a smartphone. & Using a smartphone would be fun. \\
\hline Social influence & $\begin{array}{l}\text { People who are important to me think that I should use the } \\
\text { smartphone. }\end{array}$ & People who are important to me think that I should use the smartphone. \\
\hline Compatibility & $\begin{array}{l}\text { I believe that using the smartphone is suitable for me. } \\
\text { I believe that using the smartphone fits my life style. }\end{array}$ & $\begin{array}{l}\text { I believe that using the smartphone would be suitable for me. } \\
\text { I believe that using the smartphone will fit my life style. }\end{array}$ \\
\hline Perceived ease of use & $\begin{array}{l}\text { Learning to operate the smartphone was easy for me. } \\
\text { Overall, I find the smartphone easy to use. }\end{array}$ & $\begin{array}{l}\text { Learning to operate the smartphone would be easy for me. } \\
\text { Overall, I would find the smartphone easy to use. }\end{array}$ \\
\hline \multirow[t]{3}{*}{ Perceived usefulness } & Using smartphone improves my life quality. & Using smartphone would improve my life quality. \\
\hline & Using smartphone makes my life more convenient. & Using smartphone would make my life more convenient. \\
\hline & Overall, I find smartphone useful in my life. & Overall, I find smartphone to be useful in my life. \\
\hline \multirow[t]{2}{*}{ Mobile phone anxiety } & I feel apprehensive about using smartphone. & I feel apprehensive about using smartphone. \\
\hline & It scares me to think that I could break the smartphone. & It scares me to think that I could break the smartphone. \\
\hline \multirow[t]{2}{*}{ Resistance to change } & & $\begin{array}{l}\text { I am worried that the smartphone will change the way I interact with } \\
\text { other people. }\end{array}$ \\
\hline & & I am worried that the smartphone will change the way I currently live. \\
\hline
\end{tabular}

Note: All items were measured on a 1-5 Likert-type scale, where 1 represented strong disagreement and 5 represented strong agreement. 
Table A2. Model fit of cluster solutions for the five segments.

\begin{tabular}{|c|c|c|c|c|c|c|c|c|c|c|}
\hline \multirow{2}{*}{$\begin{array}{l}\text { Segments } \\
\text { Clusters }\end{array}$} & \multicolumn{2}{|c|}{ Segment 1} & \multicolumn{2}{|c|}{ Segment 2} & \multicolumn{2}{|c|}{ Segment 3} & \multicolumn{2}{|c|}{ Segment 4} & \multicolumn{2}{|c|}{ Segment 5} \\
\hline & AIC & $\begin{array}{l}\text { Ratio of } \\
\text { Distance } \\
\text { Measures }\end{array}$ & AIC & $\begin{array}{c}\text { Ratio of } \\
\text { Distance } \\
\text { Measures }\end{array}$ & AIC & $\begin{array}{c}\text { Ratio of } \\
\text { Distance } \\
\text { Measures }\end{array}$ & AIC & $\begin{array}{c}\text { Ratio of } \\
\text { Distance } \\
\text { Measures }\end{array}$ & AIC & $\begin{array}{l}\text { Ratio of } \\
\text { Distance } \\
\text { Measures }\end{array}$ \\
\hline 1 & 1354.7 & & 2725.9 & & 7007.9 & & 6608.0 & & 7419.9 & \\
\hline 2 & 1158.1 & $2.1^{*}$ & 2442.8 & $1.8^{*}$ & 6542.0 & $2.2^{*}$ & 6330.6 & $1.9^{*}$ & 6724.1 & $3.8^{*}$ \\
\hline 3 & 1089.0 & 1.2 & 2307.5 & 1.6 & 6376.0 & 1.4 & 6238.9 & 1.2 & 6601.7 & 1.2 \\
\hline 4 & 1036.5 & 1.4 & 2237.2 & 1.2 & 6275.7 & 1.2 & 6176.8 & 1.3 & 6510.8 & 1.1 \\
\hline 5 & 1013.8 & 1.2 & 2182.9 & 1.0 & 6206.3 & 1.0 & 6153.3 & 1.0 & 6434.5 & 1.1 \\
\hline 6 & 1002.9 & 1.2 & 2131.7 & 1.2 & 6143.2 & 1.1 & 6133.0 & 1.1 & 6370.7 & 1.1 \\
\hline 7 & 999.8 & 1.3 & 2093.9 & 1.0 & 6094.5 & 1.0 & 6124.8 & 1.1 & 6321.0 & 1.1 \\
\hline 8 & 1007.3 & 1.1 & 2056.5 & 1.2 & 6051.4 & 1.0 & 6122.5 & 1.2 & 6282.9 & 1.1 \\
\hline 9 & 1018.8 & 1.1 & 2034.9 & 1.0 & 6011.7 & 1.2 & 6137.8 & 1.0 & 6255.2 & 1.0 \\
\hline 10 & 1033.5 & 1.2 & 2014.1 & 1.1 & 5991.7 & 1.0 & 6155.0 & 1.1 & 6229.4 & 1.0 \\
\hline 11 & 1053.5 & 1.0 & 1999.3 & 1.2 & 5976.5 & 1.0 & 6182.7 & 1.0 & 6206.7 & 1.0 \\
\hline 12 & 1074.5 & 1.0 & 1992.6 & 1.0 & 5961.6 & 1.0 & 6212.7 & 1.0 & 6186.7 & 1.1 \\
\hline 13 & 1095.3 & 1.0 & 1987.7 & 1.0 & 5948.1 & 1.0 & 6243.7 & 1.1 & 6180.5 & 1.1 \\
\hline 14 & 1117.1 & 1.2 & 1984.9 & 1.0 & 5937.7 & 1.1 & 6282.5 & 1.0 & 6180.1 & 1.0 \\
\hline 15 & 1141.9 & 1.0 & 1983.4 & 1.1 & 5938.8 & 1.1 & 6322.8 & 1.1 & 6181.6 & 1.0 \\
\hline
\end{tabular}

Note: AIC - Akaike's information criterion. *Cluster solution with the largest value of ratio distance measures. 


\section{Additional author information}

Andraž Petrovčič, Ph.D., is an Assistant Professor and a Research Fellow at the Centre for Social Informatics in the Faculty of Social Sciences at University of Ljubljana, Slovenia. His research interests include mobile usability, age-friendly interaction design, and sociotechnical aspects of older adults' interactions with new technologies for independent living at home.

Ana Slavec, Ph.D., obtained her doctorate in statistics from the Faculty of Social Sciences at the University of Ljubljana. Her work is mostly related to survey research methods, in particular questionnaire design and data quality issues. Currently she is a consulting statistician at InnoRenew CoE.

Vesna Dolničar, Ph.D., is an Assistant Professor of Social Informatics in the Faculty of Social Sciences, University of Ljubljana, Slovenia. She has been involved in more than 20 (inter)national research projects (e.g. FP6, Interreg, COST Actions, LLP, Erasmus+, EC tenders) related to the fields of digital inequalities and acceptability of e-care and e-health solutions. 